OPEN ACCESS

Edited by:

Weiwen Zhang,

Tianjin University, China

Reviewed by:

Dong-Woo Lee,

Kyungpook National University,

South Korea

Xiaoqiang Jia,

Tianjin University, China

Shicheng Chen,

Michigan State University, USA

*Correspondence:

Julien Brillard,

INRA, UMR408 Sécurité et Qualité des Produits d'Origine Végétale,

F-84000 Avignon, France

julien.brillard@univ-montp2.fr

Specialty section:

This article was submitted to

Microbial Physiology and Metabolism,

a section of the journal

Frontiers in Microbiology

Received: 13 May 2015

Accepted: 23 July 2015

Published: 05 August 2015

Citation:

Diomandé SE, Nguyen-The C,

Guinebretière $M-H$, Broussolle $V$ and Brillard J (2015) Role of fatty acids in Bacillus environmental adaptation

Front. Microbiol. 6:813. doi: 10.3389/fmicb.2015.00813

\section{Role of fatty acids in Bacillus environmental adaptation}

\author{
Sara E. Diomandét,2, Christophe Nguyen-The ${ }^{1,2}$, Marie-Hélène Guinebretière ${ }^{1,2}$, \\ Véronique Broussolle ${ }^{1,2}$ and Julien Brillard ${ }^{1,2,3 *}$
}

'INRA, UMR408 Sécurité et Qualité des Produits d'Origine Végétale, Avignon, France, ${ }^{2}$ Université d'Avignon, UMR408 Sécurité et Qualité des Produits d'Origine Végétale, Avignon, France, ${ }^{3}$ UMR 1333 DGIMI, INRA, Université de Montpellier, Montpellier, France

The large bacterial genus Bacillus is widely distributed in the environment and is able to colonize highly diverse niches. Some Bacillus species harbor pathogenic characteristics. The fatty acid (FA) composition is among the essential criteria used to define Bacillus species. Some elements of the FA pattern composition are common to Bacillus species, whereas others are specific and can be categorized in relation to the ecological niches of the species. Bacillus species are able to modify their FA patterns to adapt to a wide range of environmental changes, including changes in the growth medium, temperature, food processing conditions, and $\mathrm{pH}$. Like many other Gram-positive bacteria, Bacillus strains display a well-defined FA synthesis II system that is equilibrated with a FA degradation pathway and regulated to efficiently respond to the needs of the cell. Like endogenous FAs, exogenous FAs may positively or negatively affect the survival of Bacillus vegetative cells and the spore germination ability in a given environment. Some of these exogenous FAs may provide a powerful strategy for preserving food against contamination by the Bacillus pathogenic strains responsible for foodborne illness.

Keywords: Bacillus genus, adaptation, FAS II, FA degradation, exogenous FAs

\section{Introduction}

Most vital bacterial cell functions are attributed to the plasma membrane (Parsons and Rock, 2013), particularly its ability to form a permeable barrier, pump essential metabolites and macromolecules into the cell and prevent the entry of undesirable solutes from the external environment (Weber and De Bont, 1996; Ramos et al., 2001). To adapt to a wide range of environments, bacteria have the ability to control the biophysical properties of their membranes (Zhang and Rock, 2008; Murínová et al., 2014), including the membrane fluidity necessary for the growth and survival of bacteria in their environment (Esser and Souza, 1974; De Sarrau et al., 2012). Bacterial cell membranes are mainly composed of proteins, lipids and phospholipids (Bishop et al., 1967; Beaman et al., 1974). Glycerophospholipids (glycerol-based phospholipids) represent $\sim 90 \%$ of the macromolecules in bacteria (Neidhardt, 1996). They are mainly located on cell membranes and represent the main pool of FAs in microorganisms. In addition, FAs are important sources of metabolic energy and are important effector molecules that regulate metabolism.

The FA composition of bacterial cells varies depending on the species and has thus been used as a biomarker in taxonomy for many years (Cherniavskaia and Vasiurenko, 1983; Vasiurenko et al., 1984; Guinebretiere et al., 2013). Moreover, the FA composition of the cell membrane varies depending on environmental conditions because it plays a leading role in bacterial adaptation to environmental changes (Sinensky, 1971; Yano et al., 1998; De Sarrau et al., 2012). Exogenous FAs 
have been shown to influence the growth ability of Bacillus cells. For example, in Bacillus cereus, these exogenous FAs may impair (Lee et al., 2002) or improve growth (De Sarrau et al., 2013) depending on environmental conditions. In the last decade, the regulation of genes involved in metabolism and FA transport has been described in bacteria (Schujman et al., 2003; Pech-Canul et al., 2011), leading to the identification of regulators (Schujman et al., 2003; Dirusso and Black, 2004).

The genus Bacillus is the largest, most diverse and most prominent genus of aerobic endospore-forming bacteria (Fritze, 2004). In 2015, this genus contained $\sim 299$ species and 7 subspecies (Euzeby, 2015). Bacillus strains are widely distributed in the environment, belong to different niches and include strains with economic and health interests. For instance, species of the genus Bacillus can have important roles in industrial processes (De La Fuente-Salcido et al., 2013; Liu et al., 2014; Pasvolsky et al., 2014), and some strains are also human pathogens (Lamanna and Jones, 1963; Bartoszewicz et al., 2013).

This review focuses on the nature of FAs in Bacillus and their role in adaptation to their close environment, addressing both the adaptation of species to their specific ecological niches and the adaptation of the bacterial cell to a changing environment. We describe and discuss the FA composition of Bacillus species by identifying common and specific elements of their FA pattern in relation to their ecological niches, thus examining the versatility of the FA pattern in relation to their biosynthesis during adaptation in various environments. Finally, we address the impact of exogenous FAs on the growth capacity of Bacillus species.

\section{Nature and Synthesis of the Main FAs in the Bacillus Genus}

\section{Description of FA Profiles in the Bacillus Genus}

Like other Gram-positive bacteria, Bacillus species have three main groups of FAs: branched-chain FAs, straight-chain FAs, and complex FA types (such as cyclic, hydroxyl or epoxy FAs; Harris, 1996; Figure 1). Compared with other genera of Gram-positive bacteria, such as Micrococcus, Clostridium, and Corynebacterium, the genus Bacillus is characterized by a relative homogeneity of its FA composition across species (Moss and Lewis, 1967; Harris, 1996). To date, no Bacillus strains have been described with only branched-chain or straight-chain FAs. Another characteristic of this genus is that linear saturated FAs such as $\mathrm{C}_{14: 0}$ or $\mathrm{C}_{16: 0}$, which are encountered in the majority of microorganisms, are generally minor constituents in the genus Bacillus (Kaneda, 1977). Bacillus species are also characterized by displaying three major polar lipids: the phospholipids phosphatidylethanolamine, phosphatidylglycerol, and diphosphatidylglycerol (Bishop et al., 1967; Lang and Lundgren, 1970; Qiu et al., 2009; Zhai et al., 2012; Seiler et al., 2013; Yu et al., 2013; Choi and Cha, 2014; Jiang et al., 2014; Kosowski et al., 2014; Van Pham and Kim, 2014). However, some aminophospholipids are also found in the membranes of certain Bacillus strains (Bishop et al., 1967; Kang et al., 2013; Seiler et al., 2013; Wang et al., 2013; Choi and Cha, 2014).

\section{Branched-Chain FAs}

A singularity of the Bacillus genus is the abundance of branchedchain FAs (Figure 1; Kaneda, 1977; Kämpfer, 1994), with a predominance of branched chain iso and anteiso FAs containing 12-17 carbons (Berkeley et al., 2002). Branched-chain FAs also include $\omega$-alicyclic FAs with or without modifications such as unsaturation and hydroxylation. Branched-chain FAs represent up to $98 \%$ of the total FAs depending on the species (Kaneda, 1969). More precisely, iso- $\mathrm{C}_{15: 0}$, anteiso- $\mathrm{C}_{15: 0}$, iso$\mathrm{C}_{16: 0}$, iso- $\mathrm{C}_{17: 0}$, and anteiso- $\mathrm{C}_{17: 0}$ represent the major FAs typically found in Bacillus species (Kämpfer, 1994; Song et al., 2000). Branched-chain FAs display a lower melting point temperature than their equivalent straight-chain FAs. Their presence in the membrane is therefore expected to increase its fluidity.
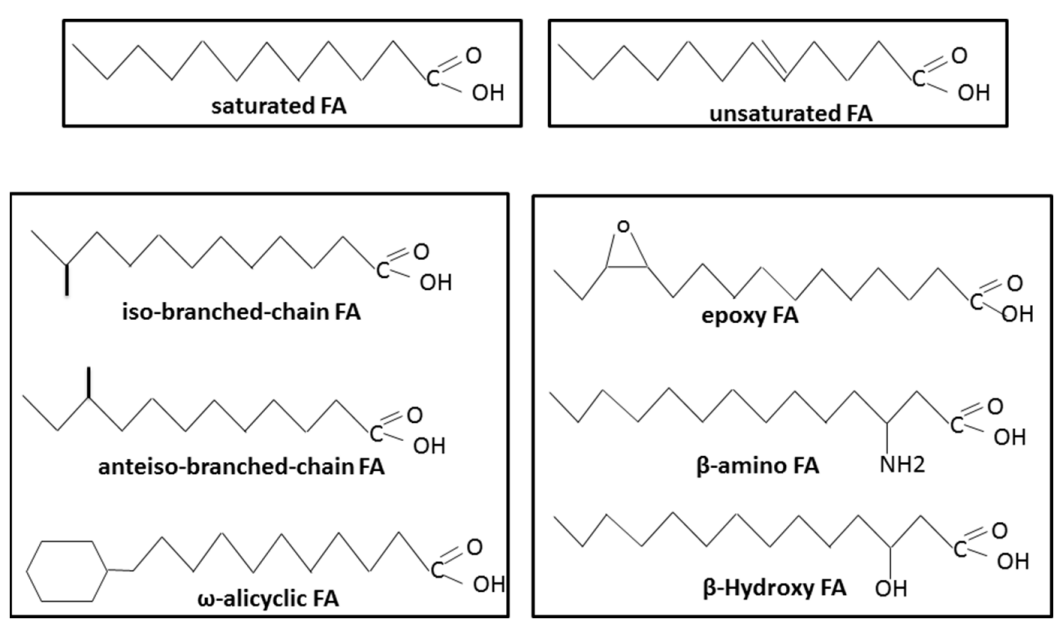

FIGURE 1 | Different types of fatty acids (FAs) present in Bacillus species. 


\section{Unsaturated FAs}

According to Kaneda, the proportion of unsaturated fatty acids (UFAs) varies in the genus Bacillus from 0 to $28 \%$ of the total FAs under optimal growth conditions (Kaneda, 1977). In Bacillus strains, UFAs consist almost exclusively of monounsaturated FAs at optimal growth temperature (Kaneda, 1977; Figure 1). Different systems of nomenclature are commonly used to describe UFAs. In the present review, we use the $\Delta \mathrm{x}$ (or delta$\mathrm{x})$ nomenclature, in which each double bond is indicated by $\Delta \mathrm{x}$; the double bond is located on the xth carbon-carbon bond, counting from the carboxylic acid end of the molecule. The most common mono-unsaturated FAs generally encountered in living organisms are $\Delta 9$ isomers. However, most of the Bacillus strains also display $\Delta 5, \Delta 8$, and $\Delta 10$ isomers (Kaneda, 1977; Brillard et al., 2010; De Sarrau et al., 2012). As for the branched-chain FAs, UFAs display a lower melting point temperature than their equivalent saturated FAs and contribute to membrane fluidity.

\section{Complex FAs}

Several Bacillus species display unusual FAs. These complex FAs are generally hydroxy, amino, and epoxy FAs (Figure 1). $\beta$-hydroxy FAs or $\beta$-amino FAs, regardless of their saturation or branched structure, are linked to polypeptides and form surfactant and antimicrobial agents (Ongena and Jacques, 2008; Baindara et al., 2013; Mondol et al., 2013; Romano et al., 2013). Epoxy FAs, which consist of FAs with one or two epoxy group(s), can be produced by Bacillus genus species, and some possess antimicrobial properties (Celik et al., 2005; Hou, 2008). Unlike the branched and unsaturated FAs described above, these complex FAs have not been described as components of the Bacillus membrane.

\section{Major FAs and Phospholipid Biosynthesis in Bacillus \\ Saturated FA Biosynthesis}

In living organisms, fatty acid synthesis (FAS) comprises a repeated cycle of reactions consisting of the condensation, reduction, dehydration, and subsequent reduction of carboncarbon bonds. In higher eukaryotes, these reactions are performed by a large multifunctional protein forming the socalled FAS type I pathway (Chirala et al., 1997). FAS type II pathway reactions are catalyzed by discrete enzymes in bacteria, plant chloroplasts, and in the eukaryotic protozoan Plasmodium falciparum (Marrakchi et al., 2002; Freiberg et al., 2004; Van Schaijk et al., 2014). Two (or more) isoenzymes may be available to catalyze a given step of the pathway, although these enzymes may differ in substrate specificity and, hence, physiological function (Rock and Cronan, 1996). The set of genes that performs the reactions in the pathway are generally highly related and clearly identified among the Bacillus species.

The biosynthesis of FAs is the first step in the formation of membrane lipids and represents a vital feature of bacterial physiology. This pathway has been extensively studied in Gramnegative Escherichia coli and Gram-positive Bacillus subtilis, which serve as models for understanding type II systems in other bacteria. The basic steps of the FAS cycle are common to all bacteria, and the genes encoding the enzymes are generally conserved (Marrakchi et al., 2002). We will describe the pathway that has been studied in B subtilis (Marrakchi et al., 2002; White et al., 2005; see Figure 2), highlighting differences in comparison to E. coli.

The first group of enzymes constitutes the initiation module (Figure 2). This group is a multisubunit enzyme that consists of acetyl coenzyme A (acetyl-CoA) carboxylase (ACC), which catalyzes a key step in intermediary metabolism that converts acetyl-CoA to malonyl-CoA. The overall ACC reaction requires four gene products: AccA, AccB, AccC, and AccD. Malonyl-CoA is transferred to the acyl-carrier-protein synthase enzyme (ACP) by the malonyl-CoA:ACP transacylase (FabD) to form malonylACP (Marrakchi et al., 2002; White et al., 2005). FA synthesis is then initiated by the condensation of malonyl-ACP as the primer with acetyl-CoA as the acceptor.

This first condensation step is catalyzed by $\beta$-ketoacyl-ACP synthase III (FabH) to form $\beta$-ketobutyryl-ACP (a $\beta$-ketoacylACP) and $\mathrm{CO}_{2}$. This process initiates a cycle of elongation of the acyl-ACP by two carbons units. A repetitive series of reactions occurs, with the addition of two-carbon units per cycle, until a final saturated FA is formed. The elongation module consists of protein condensation on an acyl-ACP primer with malonyl-ACP. The first reaction in this cycle is the NADPHdependent reduction of $\beta$-ketoacyl-ACP to $\beta$-hydroxyacyl-ACP by $\beta$-ketoacyl-ACP reductase (FabG). The obtained $\beta$-hydroxyl intermediate is dehydrated to yield trans-2-enoyl-ACP, which is catalyzed by $\beta$-hydroxyacyl-ACP dehydratase (FabZ). The final step of the cycle is the $\mathrm{NAD}(\mathrm{P}) \mathrm{H}$-dependent reduction of the double bond in the trans-2-enoyl-ACP intermediate by an enoyl-ACP reductase [enoyl-ACP reductase I (FabI), enoylACP reductase III (FabL)] to form an acyl-ACP. $\beta$-ketoacyl-ACP synthase II (FabF) initiates the subsequent elongation cycles via the condensation of malonyl-ACP with acyl-ACP. Indeed, in contrast to E. coli, which expresses both FabF and FabB for the condensation steps, the sole condensation enzyme in B. subtilis for the subsequent elongation steps of FAS is FabF (Schujman et al., 2001).

To summarize, the three steps of FA biosynthesis are (i) initiation or synthesis of precursor molecules, (ii) condensation, and (iii) elongation cycles.

\section{Branched-Chain FA Biosynthesis}

Bacillus subtilis and all of the Bacillus genus species produce mainly branched-chain FAs. For the synthesis of this FA group, the same set of FAS enzymes is used. It has been shown that B. subtilis possesses two FabH isoenzymes, FabHA and FabHB, both of which preferentially utilize branched-chain acylCoA (Figure 2). Indeed, these enzymes carry out the initial condensation reaction of FA biosynthesis using acetyl-CoA as a primer, and they also utilize iso- and anteiso-branched-chain acyl-CoA primers as substrates, leading to the production of, primarily, iso- and anteiso-branched chain FAs (Choi et al., 2000). Acetyl-CoA is used as a substrate only for the synthesis of straight-chain FAs. Branched-chain FAs have been shown to arise from branched-chain amino acid (BCAA) metabolism (Willecke and Pardee, 1971; Kaneda, 1991), consisting of valine, leucine, and isoleucine. The metabolism of these amino acids 


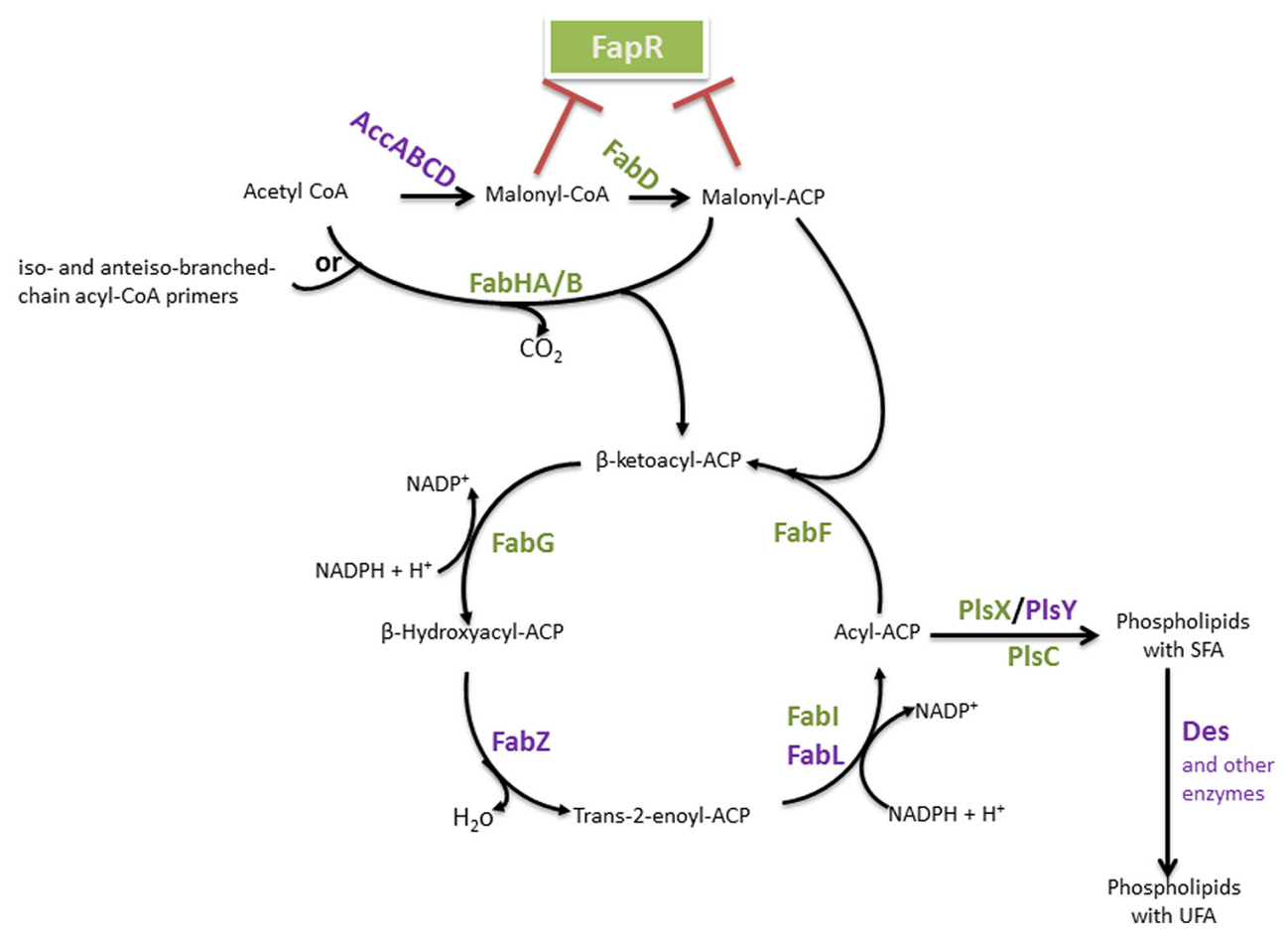

FIGURE 2 | Bacillus FAS II pathway and FA integration into phospholipids. The enzymes are identified in bold. The FapR major regulator of this pathway is represented, and enzymes which encoding genes belong to the fap regulon are indicated in green. Red blunt-head lines indicate a repression. AccABCD, acetyl-CoA carboxylase $A B C D$; FapR, fatty acid and phospholipid biosynthesis regulator; FabD,
malonyl-CoA:ACP transacylase; FabH, $\beta$-ketoacyl-ACP synthase III, FabZ, $\beta$-hydroxyacyl-ACP dehydratase, Fabl, enoyl-ACP reductase I; FabL, enoyl-ACP reductase III; FabF, $\beta$-ketoacyl-ACP synthase II; PIsX, acyl-acyl-ACP-phosphate acyltransferase; PIsY, acyl-phosphateglycerol-phosphate acyltransferase; PIsC, 1-acylglycerol-3-P acyltransferase; Des, desaturase. produces short-chain branched acyl-CoAs, such as isobutyric-, isovaleric-, and 2-methylbutryric-CoA, respectively, which serve as primers for type II FA synthesis in place of acetyl-CoA (Willecke and Pardee, 1971; Choi et al., 2000; He and Reynolds, 2002). Isoleucine is the precursor of anteiso-branched chain FAs, while leucine and valine give rise to the primers for iso-branched FAs (Kaneda, 1977, 1991). The substrate specificity of the FabHcondensing enzyme is a determining factor in the biosynthesis of branched-chain FAs by FAS II (Choi et al., 2000); FabHA and $\mathrm{FabHB}$ demonstrate a slight preference for anteiso and iso precursors, respectively.

The branched-chain $\alpha$-ketoacid decarboxylase, which has been shown to be essential for branched-chain FA biosynthesis, catalyzes the decarboxylation of $\alpha$-ketoacids derived from BCAAs to generate branched-chain acyl-CoA primers (Willecke and Pardee, 1971; Lu et al., 2004). In B. subtilis, a mutation in the gene encoding this enzyme resulted in auxotrophy for branchedchain FA precursors derived from isoleucine, valine, and leucine (Willecke and Pardee, 1971; Boudreaux et al., 1981).

\section{Unsaturated FA Biosynthesis}

Fatty acid synthesis type II has been shown to be active in both aerobic and anaerobic UFA synthesis pathways in E. coli because it does not require molecular oxygen (Scheuerbrandt and Bloch, 1962; Cronan and Vagelos, 1972). However, in Bacillus species, $f a b A$ and $f a b B$ are lacking, which have been described in $E$. coli to be responsible for UFA biosynthesis. In all of the reported investigations, the biosynthesis of UFAs in Bacillus species requires oxygen (Beranova et al., 2010; De Sarrau et al., 2012).

Bacillus subtilis has been shown to have a single acyl-lipid oxygen-dependent desaturase, designated Des (Aguilar et al., 1998), that inserts a cis-double bond at the $\Delta 5$ position of the acyl chains of membrane phospholipids (Kaneda, 1972). A $\Delta 5$ desaturase has also been described in B. megaterium (Fulco, 1967) and B. cereus (Chazarreta Cifre et al., 2013). Ferredoxin and two flavodoxins (YkuN and YkuP) were identified to be redox partners of $\Delta 5$-desaturase because they act as electron donors in the desaturation reaction (Chazarreta-Cifre et al., 2011). This finding suggests that the three proteins might function physiologically in the biosynthesis of unsaturated FAs in Bacillus species (Chazarreta-Cifre et al., 2011). Some species, such as $B$. cereus, possess an additional $\Delta 10$-desaturase, which inserts a cis-double bond at the $\Delta 10$ position of the acyl chains of membrane phospholipids (Chazarreta Cifre et al., 2013).

\section{Phospholipid Biosynthesis}

Fatty acids mostly occurs in the form of phospholipids, and phosphatidic acid is the basic structure of the 
glycerophospholipids. Phosphatidic acid (PtdOH) is the biosynthetic product of the esterification of two FAs onto the two hydroxyl groups of glycerol-3-phosphate (G3P). G3P is a phosphate ester of the 3-carbon sugar glyceraldehyde, and the only known de novo pathway for the synthesis of this molecule in bacteria is the reduction of dihydroxyacetone phosphate by G3P synthase (GpsA; Kito and Pizer, 1969; Cronan and Bell, 1974; Ray and Cronan, 1987; Beijer et al., 1993; Morbidoni et al., 1995). PtdOH biosynthesis starts with the acylation of glycerol-3-phosphate (G3P) to form 1-acyl-G3P. Similarly to most Gram-positive bacteria, two enzyme systems carry out the first reaction in B. subtilis: PlsX (acyl-acyl-ACP-phosphate acyltransferase) and PlsY (acyl-phosphate-glycerol-phosphate acyltransferase) (Figure 2; Lu et al., 2007; Yoshimura et al., 2007). The soluble enzyme PlsX converts acyl-ACP to acyl-phosphate, and the membrane-associated PlsY transfers the acyl group from acyl-phosphate to glycerol 3-phosphate (Lu et al., 2007). Acylation of the 2-position of the 1-acyl-G3P is catalyzed by PlsC, a membrane-bound 1-acylglycerol-3-P acyltransferase that predominately uses acyl-ACP, although some PlsCs also use acyl-CoA. Indeed, FAs from the environment may be converted into acyl-CoA derivatives and incorporated into the bacterial membrane (Fulco, 1972; Krulwich et al., 1987; Lu et al., 2007).

\section{Regulation of FA Metabolism}

The FA pool results from FA biosynthesis, FA incorporation into membrane phospholipids and FA degradation. FA biosynthesis is an energetically expensive process, which explains why the rate of FA production is tightly regulated to ensure that the supply of membrane phospholipids corresponds exactly to the needs of the cell. Indeed, the inhibition of phospholipid synthesis has been shown to result in a rapid decrease in the rate of FA synthesis and in the accumulation of acylated-derivatives of ACP (Rock and Jackowski, 1982; Heath and Rock, 1996). During the optimal growth or responses to changes in the environment of Bacillus, the FA composition is regulated to maintain cell membrane homeostasis. Here, we will review some key regulators of FA metabolism (Figure 3). Most of these regulators have been described in B. subtilis.

\section{Regulation of the FA Pool During Optimal Bacillus Metabolism and Sporulation}

In $B$. subtilis, the expression of FAS II genes is tightly regulated by the transcriptional regulator FapR (Figure 2). FapR regulates many genes involved in FA and lipid synthesis (the fap regulon) but not those encoding the ACC multisubunit enzyme. The genes fabHA-fabF, fapR-plsX-fabD-fabG, fabI, fabHB, yhfC (putatively encoding a transmembrane protein likely involved

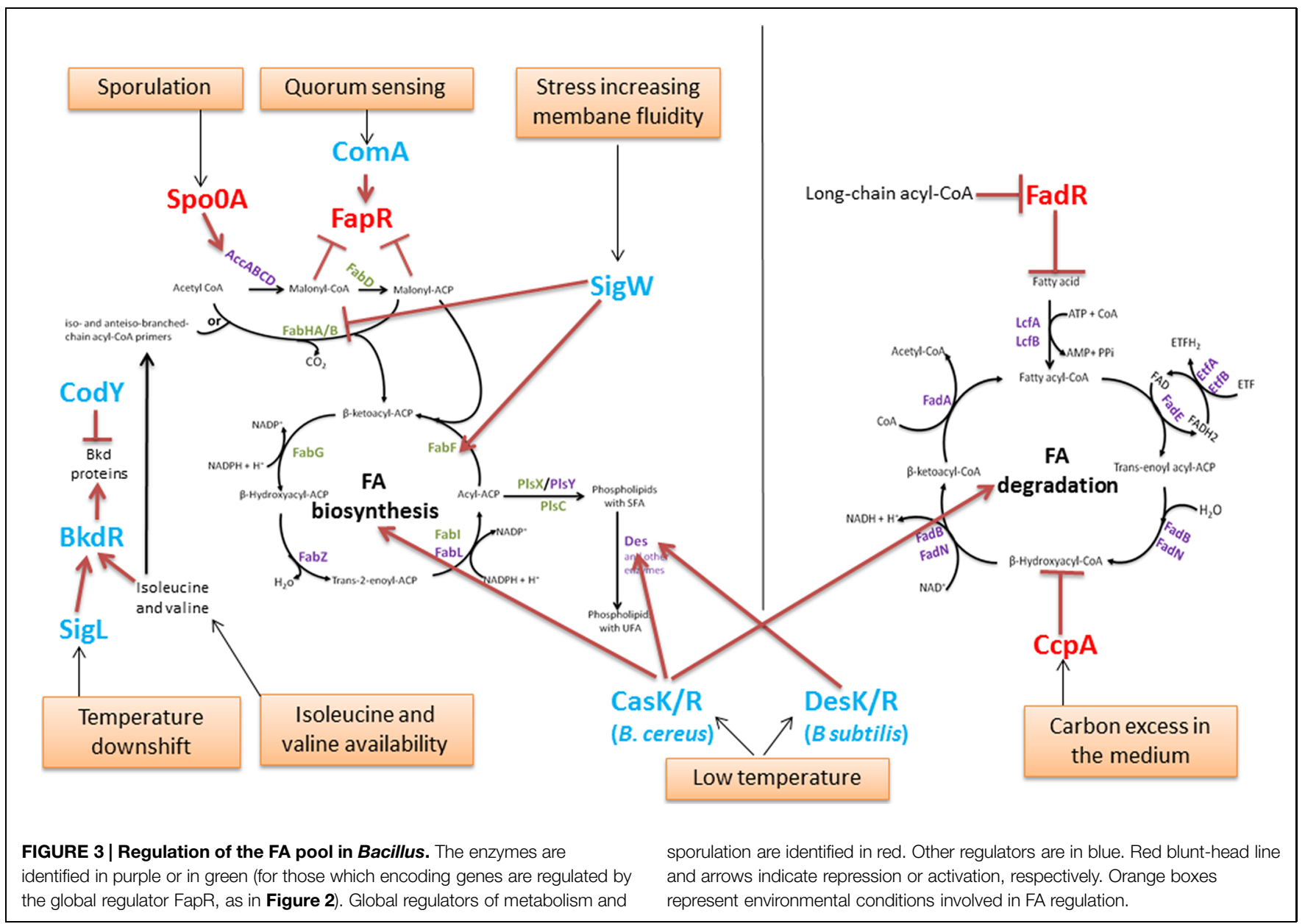


in FA synthesis) and $p l s C$, with $p l s X$ and $p l s C$ involved in phospholipid biosynthesis, belong to the fap regulon (Schujman et al., 2003; Fujita et al., 2007). FapR is highly conserved in many Gram-positive organisms, including all of the species in the Bacillus, Listeria, Staphylococcus, and Clostridium genera and other related genera (Schujman et al., 2003). FapR is repressed by the first two intermediates of FAS, malonyl-CoA and malonylACP (Figures 2 and 3 ), to balance the production of membrane phospholipids and thus maintain membrane lipid homeostasis.

The degradation of FA via $\beta$-oxidation has a crucial function only under certain physiological conditions (Fujita et al., 2007), e.g., during sporulation (Gonzalez-Pastor et al., 2003) or calcium carbonate biomineralization (Barabesi et al., 2007). The B. subtilis FA degradation is regulated by FadR (Figure 3) from the TetR-family of transcriptional regulators, a homolog of FabR found in Gram-negative bacteria. FadR represses FA $\beta$-oxidation degradation by repressing five $f a d$ operons: $l c f A-f a d R-f a d B-$ etfB-etfA, lcfB, fadN-fadA-fadE, fadH-fadG, and fadF-acdA-rpoE, (Matsuoka et al., 2007; Fujihashi et al., 2014). FadR binds to boxes located in the promoter regions of these operons. The FadR activity is inhibited by the long-chain acyl-CoAs (14-20 carbon molecules), leading to the induction of FA degradation (Matsuoka et al., 2007; Fujihashi et al., 2014).

The catabolic control protein CcpA represses many catabolic genes and operons, consisting mainly of those involved in carbon, nitrogen, and phosphate metabolism. It has also been described to repress the five operons belonging to the FadR regulon, including the $f a d R$ operon (Tojo et al., 2011).

Spo0A represents a master transcription factor in Bacillus strains because the Spo0A regulon comprises more than 500 genes (Piggot and Hilbert, 2004) and plays a major role in the formation of Bacillus spores. Active and robust de novo FA and membrane lipid synthesis occur during sporulation (Schujman et al., 1998; Pedrido et al., 2013). Spo0A controls the accDA operon involved in malonyl-CoA synthesis and, consequently, regulates FAS II by the negative modulation of FapR (Pedrido et al., 2013).

\section{Examples of Regulations in the Bacillus FA Pool Based on Specific Responses}

$\mathrm{BkdR}$ is a regulator that has been described in B. subtilis; it controls the utilization of isoleucine and valine as sole nitrogen sources (Debarbouille et al., 1999). Indeed, BkdR positively regulates the $b k d$ operon, which consists of seven genes encoding enzymes that catalyze the conversion of BCAAs into precursors of branched FAs (Figure 3). The expression of the bkd operon has been shown to be induced by the presence of isoleucine or valine in the growth medium and to depend on the presence of the sigma factor SigL (Peng et al., 2015). In addition, it is induced by a temperature downshift from 37 to $18^{\circ} \mathrm{C}$ in $B$. subtilis (Nickel et al., 2004). SigL and BkdR have been shown to participate in B. subtilis cold-shock adaptation (Wiegeshoff et al., 2006).

Branched-chain amino acids comprise isoleucine, leucine, and valine. Their biosynthesis must be thoroughly controlled to ensure that appropriate amounts of precursors are available for the synthesis of branched-chain FAs and of proteins and coenzyme A (Brinsmade et al., 2010). CodY is a global transcriptional regulator that is widespread among Bacillus (Slack et al., 1995; Hsueh et al., 2008; Van Schaik et al., 2009), responsible for responding to these metabolites and regulating the genes that direct their synthesis (Brinsmade et al., 2010). Moreover, CodY negatively regulates the $b k d$ operon involved in the degradation of isoleucine and valine (Debarbouille et al., 1999).

ComA, which belongs to the major quorum response Com signaling pathway in B. subtilis, was shown to regulate, both directly and indirectly, the expression of genes involved in FA metabolism, including FapR (Comella and Grossman, 2005). Indeed, the expression of the FapR regulon was shown to be reduced in a comA null mutant (Comella and Grossman, 2005). Because adjustment of the lipid composition of membranes is important for growth and gene regulation under a variety of different conditions, Comella and Grossman (2005) hypothesized that during the quorum response, changes in the lipid composition of the membrane may be important for accommodating the wide variety of developmental changes that might occur during competence, sporulation and biofilm formation.

The extracellular function (ECF) of SigW $\sigma$ factor in B. subtilis is involved in the stress response to compounds that increase membrane fluidity (Kingston et al., 2011). The binding of SigW to the SigW-dependent promoter within the fabHA-fabF operon down-regulates $\mathrm{fabHA}$ encoding for the enzyme that initiates the synthesis of new FA chains (preferentially from branched precursors), but it also up-regulates $f a b F$ encoding the enzyme that initiates a new elongation cycle of the FA chain, leading to a higher proportion of straight chain FAs and a longer average chain length of the membrane phospholipids. These membrane alterations result in reduced bilayer fluidity and an increased resistance to detergents and antimicrobial compounds produced by other Bacillus species (Kingston et al., 2011).

Some two-component systems (TCSs) have been described regarding their role as thermosensors to maintain membrane homeostasis.

Bacillus subtilis DesK/R was the first TCS to be described for the maintenance of membrane fluidity during low-temperature adaptation in a Bacillus strain (Aguilar et al., 2001). DesK/R was shown to be effective either at constant cold temperatures or after a temperature downshift in response to sensing a decrease in membrane fluidity (Cybulski et al., 2002).The sensor protein DesK is a multipass transmembrane histidine kinase that senses an increase in membrane thickness when the growth of B. subtilis decreases (Aguilar et al., 2001; Cybulski et al., 2010; Inda et al., 2014). Its cognate response regulator DesR then regulates the expression of the $\Delta 5$-desaturase gene des, which is responsible for increasing the proportion of membrane UFAs and thus maintaining an optimal membrane fluidity (Aguilar et al., 2001).

CasK/R has been recently described as a TCS that is involved in B. cereus cold adaptation (Diomandé et al., 2014). In contrast to the membrane protein DesK, CasK presumably has a cytoplasmic location (Diomandé et al., 2014). Recent evidence has shown that this TCS regulates genes involved in both FA synthesis and FA degradation (Diomandé et al., 2015a), including two genes 
encoding the desaturases $\operatorname{des} A$ and $\operatorname{des} B$ in $B$. cereus. During growth at low temperatures, CasK/R regulates the membrane FA composition and, mainly, UFA synthesis by regulating $\operatorname{des} A$. DesA is a $\Delta 5$-desaturase, homolog of the B. subtilis Des protein. Several studies identified in Bacillus species the $\Delta 5$ desaturase that is involved in adaptation at low temperatures (Fulco, 1967, 1969, 1972; Kaneda, 1972; Bredeston et al., 2011). The two examples of DesK/R and CasK/R illustrate that the regulation of membrane fluidity at low temperature via UFAs may involve different TCSs in Bacillus species.

In conclusion, in these two examples, the membrane fluidity appears to be maintained and, therefore, to adapt to the FA pool. Bacillus cells use several regulators that can act at four levels: precursor metabolism, FA and phospholipid synthesis, and FA degradation. Depending on the Bacillus environment, physical parameters such as temperature or stressful conditions influencing the membrane fluidity, but also chemical parameters such as nutrient availability, specific regulators are recruited for the adaptation and preservation of the membrane.

\section{FA Profiles Vary Among Bacillus Species}

The Bacillus genus is a large genus in which the number of novel strains characterized is increasing (Choi and Cha, 2014; Kosowski et al., 2014; Zhao et al., 2014). The FA profiles of Bacillus genus strains are used, in addition to various other molecular data, as a biomarker for taxonomy.

The tools used for FA-based taxonomy have been standardized. For FA pattern analysis, the FAs were extracted in the form of FA methyl esters (FAMEs) using the MIDI method as previously described (Sasser, 1990; Connor et al., 2010; Guinebretiere et al., 2013). This MIDI method has been commonly used since the end of the 1990s to complement other standard discriminating tools and perform taxonomy, in particular for the Bacillus genus (Song et al., 2000). The MIDI method has also been used to describe new species of the genus (Reddy et al., 2008; Logan et al., 2009; Yu et al., 2013; Kosowski et al., 2014; Subhash et al., 2014).

Here, we discuss the extent to which the Bacillus FA patterns can discriminate species and their temperature adaptations.

\section{Kaneda's Classification} Unsaturated FAs

According to Kaneda, the Bacillus genus strains can first be divided into three groups depending on their UFA proportions (Kaneda, 1977; Figure 4).

First, species displaying a very low or insignificant proportion of UFAs, from 0 to less than $3 \%$ of the total FAs, formed the first group. This group included mesophilic and thermophilic strains, such as B. subtilis, B. megaterium, B. stearothermophilus, and $B$. acidocaldarius (see Figure 4). Further studies confirmed

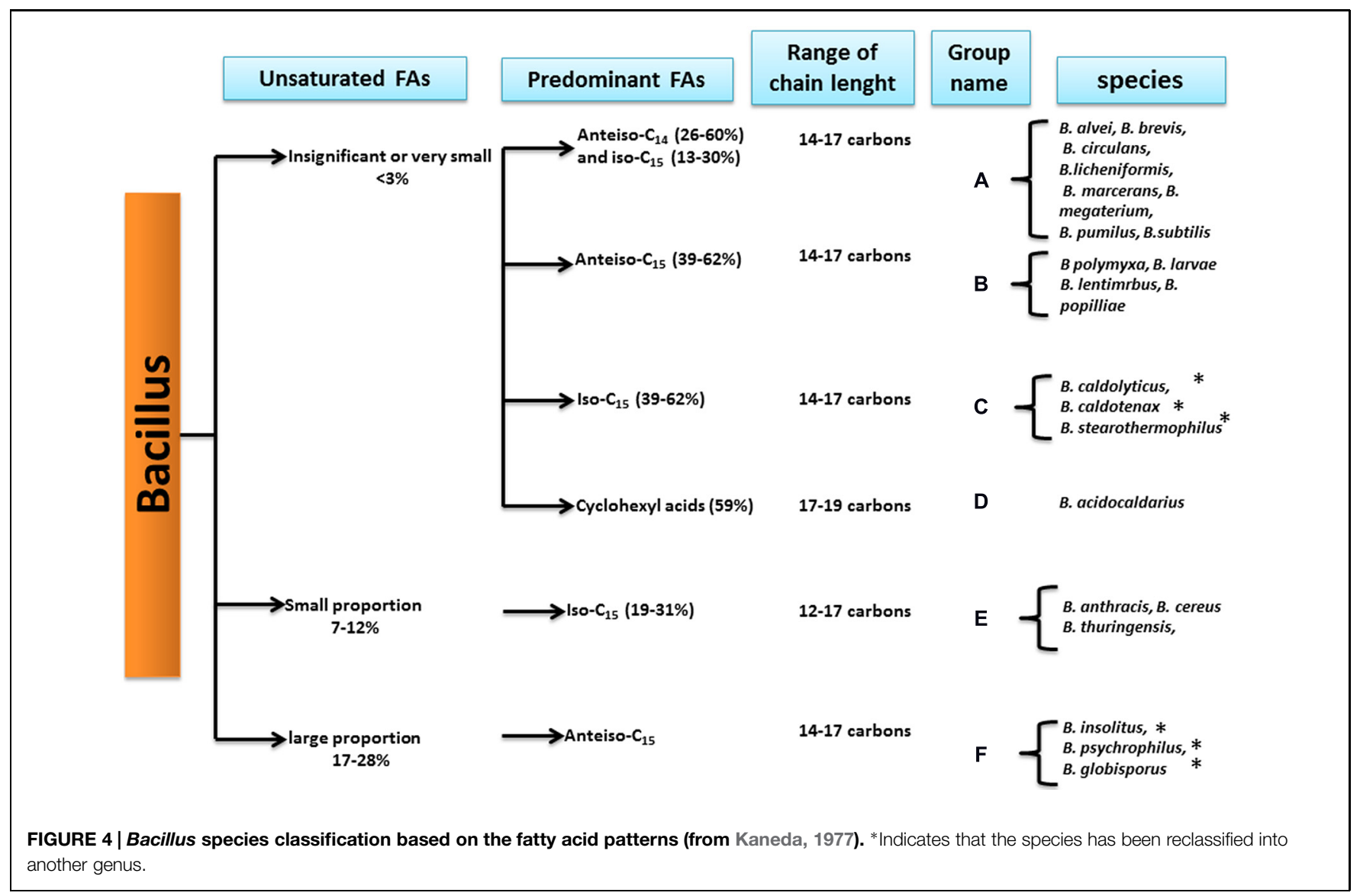


that at optimal temperatures, B. subtilis strains displayed nearly zero UFAs (Bishop et al., 1967; Grau and De Mendoza, 1993).

The second group consisted of strains displaying a small proportion of UFAs representing from 7 to $12 \%$ of the total FAs. This group included strains from the $B$. cereus group. In addition, some bacteria in this group, such as $B$. weihenstephanensis and $B$. mycoides, which are psychrotolerant strains of $B$. cereus sensu lato, were described after the Kaneda classification.

The third group consists only of psychrotolerant species of the genus, which have been described to present larger proportions of UFAs (17-28\%). Studies of the three psychrotolerant species revealed that they displayed a larger proportion of UFA when compared to other strains, e.g., B. globisporus $(26.1 \%$ of the total FAs), B. insolitus (25.1\% of the total FAs), and B. psychrophilus (18.4\% of total FAs) (Kaneda et al., 1983).

However, during this study, the growth conditions used for the studied strains were not standardized but varied according to the strains, while the actual MIDI method was used for the standardized growth conditions employed for taxonomy. Therefore, we were curious about the results when using the FA profile obtained using the MIDI method.

\section{Predominant FAs}

Based on the FA profiles, Kaneda further divided the Bacillus genus species into six groups (Kaneda, 1977), displaying specific predominant FAs combined with different levels of UFA proportions (Figure 4).

In this classification, psychrotolerant strains with high proportions of UFAs all belonged to group F with anteiso-C15:0 as the major FA. Studies investigating several psychrotrophic strains from B. globisporus, B. psychrophilus, B. insolitus (Kaneda et al., 1983), and B. pasteurii (Yoon et al., 2001) confirmed that the predominant FA was anteiso-C15:0. Even if some of these species now belong to another genus, the Sporosarcina genus, the criterion of anteiso-C15:0 as one of the major FA was used as one of the references to describe new psychrotolerant species of Bacillus [i.e., B. beringensis, which displayed anteiso-C15:0 and iso-C15:0 as major FAs (Yu et al., 2011)].

Strains of B. cereus sensu lato, which includes B. cereus sensu stricto, $B$. thuringiensis, and $B$. anthracis, are characterized by small proportions of UFAs in Kaneda's scheme and contain isoC15:0 as a major FA (Song et al., 2000), representing group E (Figure 4). Further studies strengthened this observation for the B. cereus sensu stricto strains (Brillard et al., 2010; De Sarrau et al., 2012). Moreover, a novel thermophilic species, B. cytotoxicus, belonging to $B$. cereus sensu lato, was described for possess isoC15:0 as the major FA (Guinebretiere et al., 2013; Diomandé et al., $2015 b)$. This finding is in agreement with the Kaneda grouping of B. cereus sensu lato species in group E (Figure 4).

Species with very small proportions of UFAs were subdivided by Kaneda into four subgroups according to their predominant FAs:

- Group C (Figure 4) contains thermophilic species such as B. stearothermophilus (since reclassified as Geobacillus stearothermophilus), in which the major FA is branched-chain iso-C15:0 (Cho and Salton, 1966; Yao et al., 1970).
A thermotolerant species, B. cytotoxicus, has also been shown to display the branched-chain iso-C15:0 as the predominant FA (Guinebretiere et al., 2013). B. cytotoxicus belongs to $B$. cereus sensu lato, and in this respect, it is more closely related to the Kaneda group E. Nevertheless, it has a much lower proportion of UFAs than other species of $B$. cereus sensu lato (Diomandé et al., 2015b), which is consistent with the definition of Kaneda group C.

- Group A contains the mesophilic B. subtilis and B. megaterium, and studies have shown that iso-C15:0 is the major FA (Kämpfer, 1994; Cybulski et al., 2002). In contrast to the Kaneda analysis, the other predominant FA is not anteisoC14:0 but anteiso-C15:0.

- Group B contains the cold-tolerant B. polymyxa (Guinebretiere et al., 2001; now reclassified as Paenibacillus polymyxa), which contains a particularly high proportion of anteiso C15:0 FAs (Figure 4).

- Group D corresponds to Bacillus species in which the predominant FAs are cyclohexyl FA (Figure 4), also called $\omega$-alicyclic FA (Figure 1). These Bacillus species have since been reclassified in the Alicyclobacillus genus and are characterized by both acidophilic and thermotolerant/thermophilic behavior types (Chan et al., 1971; Da Costa et al., 2009).

Thus, the classification according to the ratio of UFAs and predominant FAs proposed by Kaneda (1977) appeared to fit with both the taxonomic position and adaptation to temperature. However, the FA analytical tools evolved, and there are several exceptions to the Kaneda classification. For example, the predominant FAs in B. cerembensis, which has been described as a psychrotolerant species, appeared to be iso-C15:0 and isoC16:1 (Reddy et al., 2008) and not anteiso-C15:0. Similarly, few Alicyclobacillus species are acidophilic and thermotolerant without possessing $\omega$-alicyclic FAs (Da Costa et al., 2009).

Not all of these observations appear to be specific to the Bacillus genus. In the Clostridium genus, the mesophilic and psychrophilic strains have been characterized by a higher percentage of UFAs compared with the thermophilic strains (Chan et al., 1971), and some thermophilic Clostridia species from different thermal niches have been shown to display different predominant FA types (Chan et al., 1971).

\section{Discrimination of Bacillus Thermotypes by FAs The Specific Case of Bacillus cereus sensu lato}

Bacillus cereus sensu lato is a specific group of Bacillus strains that consists of seven phylogenetic groups characterized by different ranges of growth temperatures (Guinebretiere et al., 2008), exhibiting four major thermotypes: thermotolerant (group VII), mesophilic (groups I, III, and IV), mesophilic-psychrotolerant intermediary (group V), and psychrotolerant (groups II and VI), as shown in Table 1. In contrast to the other Bacillus strains, $B$. cereus $s l$ strains display a significant amount of FAs with short chains of 12 and 13 carbons (more than $10 \%$ of the total FAs) and a smaller amount of anteiso- $\mathrm{C}_{15: 0}$ (Kämpfer, 1994; Song et al., 2000; Haque and Russell, 2004). 
TABLE 1 | Various thermotypes of Bacillus cereus sensu lato and mean values of i16:1(5) proportion, i15/i13 ratio, HAl, a15/i15 ratio for each phylogenetic group.

\begin{tabular}{|c|c|c|c|c|c|c|}
\hline Thermotype & Growth range $\mathbf{T}^{\circ} \mathbf{C}^{1}$ & Phylogenetic groups ${ }^{1}$ & i16:1(5) \%² & $\mathrm{i} 15 / \mathrm{i13}^{2}$ & a15/i15 & HAl \\
\hline Thermotolerant & $20-50^{\circ} \mathrm{C}$ & VII & $0.02 \pm 0.01$ & $7.13 \pm 1.70$ & $0.26 \pm 0.03$ & $5.73 \pm 0.82$ \\
\hline Highly mesophilic & $15-45^{\circ} \mathrm{C}$ & III & $0.31 \pm 0.02$ & $1.57 \pm 0.04$ & $0.20 \pm 0.08$ & $3.62 \pm 0.48$ \\
\hline Mesophilic & $10-45^{\circ} \mathrm{C}$ & IV & $0.50 \pm 0.03$ & $1.14 \pm 0.10$ & $0.31 \pm 0.03$ & $3.61 \pm 0.11$ \\
\hline Mesophilic & $10-43^{\circ} \mathrm{C}$ & I & $0.05 \pm 0.01$ & $1.09 \pm 0.04$ & $0.27 \pm 0.00$ & $1.89 \pm 0.10$ \\
\hline $\begin{array}{l}\text { Mesophilic-Psychrotolerant } \\
\text { Intermediary }\end{array}$ & $10-40^{\circ} \mathrm{C}$ & V & $0.66 \pm 0.06$ & $0.91 \pm 0.13$ & $0.35 \pm 0.07$ & $4.46 \pm 0.78$ \\
\hline Psychrotolerant & $7-40^{\circ} \mathrm{C}$ & $\|$ & $1.24 \pm 0.05$ & $1.12 \pm 0.12$ & $0.35 \pm 0.08$ & $5.19 \pm 0.84$ \\
\hline Psychrotolerant & $5-37^{\circ} \mathrm{C}$ & $\mathrm{Vl}$ & $1.09 \pm 0.13$ & $0.61 \pm 0.13$ & $0.40 \pm 0.12$ & $3.27 \pm 0.84$ \\
\hline
\end{tabular}

${ }^{1}$ Guinebretiere et al. (2008), ${ }^{2}$ Diomandé et al. (2015b).

A previous study has shown that $B$. cereus sl strains display three specific predominant FAs: iso-C13:0 (i13), isoC15:0 (i15) and C16:0 (n16), and a significant proportion of UFAs (Diomandé et al., 2015b). This study showed that two parameters discriminate the strains from the various phylogenetic groups of $B$. cereus sl: the i15/i13 ratio and the C16:1 (5) proportion (Table 1). The i15/i13 ratio discriminated the major thermotypes of $B$. cereus $s l$ and tended to decrease with the psychrotolerance. Indeed, this ratio was high (i.e., $>1$, up to 7) in the thermotolerant strains of group VII, exhibiting a value of $\sim 1$ for mesophilic and intermediary strains and a low value (i.e., <1) for the psychrotolerant strains in group VI. The C16:1(5) proportion was more discriminating than the i15/i13 ratio because this proportion even differed between phylogenetic groups in close growth temperature ranges and tended to decrease with the thermotolerance (Diomandé et al., 2015b).

Thus, these data suggest that based on the FA predominance and key FA ratios, it is possible to predict the thermotype of strains of B. cereus sl. Even if the results of this study strengthen some of the observations reported by Kaneda, they also highlight the key role of specific FAs (particularly isoC13:0) in the classification of $B$. cereus sl. These differences in FA composition among different thermotypes of $B$. cereus retrospectively also explain the results published by Pirttijärvi et al. $(1998,2000)$. These authors found that the strains isolated from processed whey and paper materials displayed FA profiles that were very different from those of the reference B. cereus strains used in the MIDI database; in the case of whey, the results were very different from those of the strains isolated from raw milk. In addition, the strains obtained from the processed whey were unable to grow at cold temperatures, in contrast to the strains from raw milk (Pirttijärvi et al., 1998). These processes presumably selected strains from the most heat-tolerant thermotypes of $B$. cereus, which present peculiar differences in FA composition compared with cold-tolerant thermotypes, as described above.

\section{Bacillus and Related Genera excluding B. cereus sensu lato \\ Use of FA profiles data for discrimination of Bacillus}

In the literature relating FA profiles, two criteria are described to discriminate species of the genus Bacillus: (i) the heat adaptation index (HAI; Connor et al., 2010) which is based on temperature adaptation factors and (ii) the a15/i15 ratio (Kämpfer, 1994) which is based on the predominant FAs (FAs with the largest proportion). The i15/i13 ratio is optimized for $B$. cereus sl strains which possess an important proportion of i13:0 compared with a15:0, as outlined in the previous section. However, neither HAI nor a15/i15 is relevant for discriminating thermotypes of B. cereus sl (Table 1). Thus, this section deals with Bacillus and relatives, excluding $B$. cereus $s l$, and are mentioned as "Bacillus es" in the following text, designing 'Bacillus in every sense.'

\section{Heat adaptation index}

Connor et al. (2010) revealed that some FAs allow the discrimination of B. subtilis and B. licheniformis species that belong to different ecotypes by calculating the HAI. To determine this parameter, two factors must be calculated: (i) the high temperature adaptation factor as the sum of the proportions of the n14:0; n16:0; i14:0; i15:0; i16:0 and i17:0 FAs, (ii) the lowtemperature adaptation factor as the sum of the proportions of a15:0; a17:0; n16:1; i17:1 (n-10) and 16:1 $\omega 7 \mathrm{c}$ alcohol. The HAI is obtained by dividing the high temperature adaptation factor by the low temperature adaptation factor (Connor et al., 2010).

$$
\mathrm{HAI}=\frac{\begin{array}{c}
\mathrm{p}(\mathrm{n} 14: 0)+\mathrm{p}(\mathrm{n} 16: 0)+\mathrm{p}(\mathrm{i} 14: 0)+\mathrm{p}(\mathrm{i} 15: 0) \\
+\mathrm{p}(\mathrm{i} 16: 0)+\mathrm{p}(\mathrm{i} 17: 0)
\end{array}}{\mathrm{p}(\mathrm{a} 15: 0)+\mathrm{p}(\mathrm{a} 17: 0)+\mathrm{p}(\mathrm{n} 16: 1)+}
$$

$\mathrm{p}$ is the proportion of the FA.

\section{a15/i15 ratio}

The a15/i15 ratio (Kämpfer, 1994) exploits the two predominant FAs i15:0 and a15:0 in Bacillus, with a15:0 being the major FA in psychrotolerant strains (Kaneda, 1977).

As to our knowledge it doesn't exist any study comparing these two criteria, we wondered which one was the more appropriate to discriminate species of different thermotypes among Bacillus es by using the FA profile. We therefore choose to compare these two criteria using the Bacillus es FA pattern data obtained from MIDI extraction by (Song et al., 2000; see Table 2 for species of concern). These data, from the year 2000, include species that were later characterized to belong to other genera, 
TABLE 2 | Strains (from Song et al., 2000) used for Bacillus genus classification using FA composition, respective reviewed name and growth temperature range obtained from the Bergey's manual (Vos et al., 2011) and the database ABIS encyclopedia (Abis [ABIS v.9], n.d.).

\begin{tabular}{|c|c|}
\hline Strains & $\begin{array}{l}\text { Growth temperature } \\
\text { range }\end{array}$ \\
\hline Bacillus subtilis 170311 & ND \\
\hline B. aminovorans $94021 \mathrm{~T}$ & $5-10$ to $37^{\circ} \mathrm{C}$ \\
\hline B. amyloliquefaciens 170517 & 15 to $50^{\circ} \mathrm{C}$ \\
\hline B. amyloliquefaciens 170518 & 16 to $50^{\circ} \mathrm{C}$ \\
\hline B. amyloliquefaciens 94022 & 17 to $50^{\circ} \mathrm{C}$ \\
\hline B. atrophaeus $95007 \mathrm{~T}$ & 10 to $55^{\circ} \mathrm{C}$ \\
\hline B. atrophaeus ATCC 9372 & 10 to $55^{\circ} \mathrm{C}$ \\
\hline B. badius 94024 & 15 to $50^{\circ} \mathrm{C}$ \\
\hline B. circulans CCTCCAB 94026 & $5-20$ to $35-50^{\circ} \mathrm{C}$ \\
\hline B. coagulans CCTCCAB 92066 & $15-25$ to $55-60^{\circ} \mathrm{C}$ \\
\hline B. firmus CCTCCAB 170519 & $5-20$ to $40-50^{\circ} \mathrm{C}$ \\
\hline B. firmus CСTCCAB $94028 \mathrm{~T}$ & $5-20$ to $40-50{ }^{\circ} \mathrm{C}$ \\
\hline $\begin{array}{l}\text { B. globisporus CCTCCAB } 94031 \text { T (Sporosarcina } \\
\text { globispora) }\end{array}$ & $0-3$ to $25-30^{\circ} \mathrm{C}$ \\
\hline $\begin{array}{l}\text { B. insolitus CCTCCAB } 94032 \text { T (Psychrobacillus } \\
\text { insolitus) }\end{array}$ & $0-5$ to $25^{\circ} \mathrm{C}$ \\
\hline $\begin{array}{l}\text { B. lentimorbus CCTCCAB } 94034 \text { T (Paenibacillus } \\
\text { lentimorbus) }\end{array}$ & 20 to $35^{\circ} \mathrm{C}$ \\
\hline B. lentus CCTCCAB $94035 \mathrm{~T}$ & 10 to $40^{\circ} \mathrm{C}$ \\
\hline B. licheniformis CCTCCAB 170513 & 15 to $50-55^{\circ} \mathrm{C}$ \\
\hline B. licheniformis CCTCCAB 170514 & 16 to $50-55^{\circ} \mathrm{C}$ \\
\hline B. licheniformis CCTCCAB $94036 \mathrm{~T}$ & 17 to $50-55^{\circ} \mathrm{C}$ \\
\hline B. megaterium 170201 & $3-20$ to $35-45^{\circ} \mathrm{C}$ \\
\hline B. megaterium 170505 & $3-20$ to $35-45^{\circ} \mathrm{C}$ \\
\hline B. megaterium CCTCC AB 92075 T & $3-20$ to $35-45^{\circ} \mathrm{C}$ \\
\hline B. mojavensis CCTCC AB $96001 \mathrm{~T}$ & 10 to $55^{\circ} \mathrm{C}$ \\
\hline B. niacini CCTCC AB 95011 T & 10 to $40^{\circ} \mathrm{C}$ \\
\hline B. pumilus CCTCC AB $94044 T$ & $5-15$ to $40-50^{\circ} \mathrm{C}$ \\
\hline B. simplex CCTCC AB $94045 T$ & 20 to $40^{\circ} \mathrm{C}$ \\
\hline B. sphaericus 170511 (Lysinibacillus sphaericus) & $10-15$ to $30-45^{\circ} \mathrm{C}$ \\
\hline B. sphaericus 170512 (L. sphaericus) & $10-15$ to $30-45^{\circ} \mathrm{C}$ \\
\hline B. sphaericus CCTCC AB 92073 T (L. sphaericus) & $10-15$ to $30-45^{\circ} \mathrm{C}$ \\
\hline $\begin{array}{l}\text { B. stearothermophilus CСТСС AB } 92070 \text { T } \\
\text { (Geobacillus stearothermophilus) }\end{array}$ & $30-45$ to $65-75^{\circ} \mathrm{C}$ \\
\hline B. subtilis CCTCCAB $92068 \mathrm{~T}$ & $5-15$ to $40-45^{\circ} \mathrm{C}$ \\
\hline B. subtilis 170221 & $5-15$ to $40-45^{\circ} \mathrm{C}$ \\
\hline B. subtilis 170312 & $5-15$ to $40-45^{\circ} \mathrm{C}$ \\
\hline $\begin{array}{l}\text { B. thiaminolyticus CCTCC AB } 95017 T \text { (P. } \\
\text { thiaminolyticus) }\end{array}$ & 20 to $45^{\circ} \mathrm{C}$ \\
\hline Brevibacillus agri CCTCC AB 95005 T & $5-20$ to $40^{\circ} \mathrm{C}$ \\
\hline Brevibacillus brevis CCTCC AB $94025 T$ & $10-35$ to $40-50{ }^{\circ} \mathrm{C}$ \\
\hline P. amylolyticus CCTCC AB 95019 T & $10-15$ to $40^{\circ} \mathrm{C}$ \\
\hline P. larvae CCTCC AB $94033 T$ & 20 to $40^{\circ} \mathrm{C}$ \\
\hline P. pabuli CCTCC AB 95012 T & $5-10$ to $35-40^{\circ} \mathrm{C}$ \\
\hline P. peoriae CCTCC AB $95013 T$ & $5-10$ to $35-45^{\circ} \mathrm{C}$ \\
\hline P. polymyxa 170507 & $5-10$ to $35-45^{\circ} \mathrm{C}$ \\
\hline P. polymyxa 170508 & $5-10$ to $35-45^{\circ} \mathrm{C}$ \\
\hline P. polymyxa CCTCC AB 92076 T & $5-10$ to $35-45^{\circ} \mathrm{C}$ \\
\hline
\end{tabular}

e.g., Sporosarcina, Paenibacillus, Geobacillus, and Lysinibacillus (Pettersson et al., 1999; Nazina et al., 2001; Yoon et al., 2001; Ahmed et al., 2007).

\section{Evaluation of the two ratios HAI and 15/i15 as indicator of species thermotype}

Heat adaptation index and a15/i15 ratios are presented in Figures 5A,B respectively. Their interest for describing species thermotypes was examined below. Adaptation to temperature may have occurred by extending growth limits toward low or high temperature, resulting to different thermotypes. The most common are "psychrophilic," "mesophilic" and "thermophilic" thermotypes. However, thermotypes also includes intermediate organisms, such as mesophilic strains with psychrotophic or with thermotolerant abilities.

Firstly, the psychrophylic species Sporosarcina globispora [previously named Bacillus globisporus (Yoon et al., 2001)] displayed the lowest HAI (Figure 5A) and highest a15/i15 ratio (Figure 5B). Psychrotrophic species of the genus Paenibacillus also appeared to display the same pattern in both representations: a low HAI $(<1)$ and a high a15/i15 ratio $(>3)$. Thus, this pattern seemed to overall describe most species able to grow at cold temperatures (from psychrophilic species to mesophilic species with psychrotrophic abilities).

Secondly, 22 strains that displayed values between 1 and 3 for a15/i15 and $\sim 1$ for HAI, presumably belong to mesophilic species (B. lentus, B firmus, B. circulans, B. aminovorans, B. subtilis and closely related species $B$. amyloliquefaciens, $B$. atrophaeus, $B$. mojavensis, $B$. licheniformis and $B$. pumilus). This pattern was thus considered as specific of most mesophilic species not able to grow at cold temperatures (i.e., not psychrotrophic).

Thirdly, the thermophilic Geobacillus sterarothermophilus [previously known as B. sterarothermophilus (Nazina et al., 2001)] and the thermotolerant $B$. badius displayed a high HAI (Figure 5A) and a low a15/ i15 ratio (Figure 5B). This pattern was thus considered as indicating most of highly thermotolerant species.

\section{Limitations of such index use}

In this study, there were a number of exceptions for which the previous patterns were not followed. The psychrophilic B. insolitus [now Psychrobacillus insolitus (Krishnamurthi et al., 2010)] did not follow the psychrotolerant-specific pattern (i.e., low HAI and high a15/i15 ratio); the mesophilic $B$. sphaericus and $B$. lentimorbus harbored entirely or partly a thermotolerant-specific pattern; the thermotolerant to mesophilic B. coagulans and Brevibacillus harbored a psychrotolerant-specific pattern.

Different reasons may explain these exceptions:

(i) Intraspecies variability often taken into account to determine range of growth temperature (i.e., known thermotype) may be not truly represented by the reference strains used in this study.

(ii) In some cases the intraspecific variability may be due to bacterial complex containing different genomospecies. Indeed, numerous Bacillus complexes have been rearranged since years 2000, such as B. sphaericus, B. coagulans, $B$. circulans, $\mathrm{Br}$. brevis complexes; these rearrangements generated new Bacillus species and new genus (Heyndrickx et al., 1995; Shida et al., 1997; Pettersson et al., 1999; 


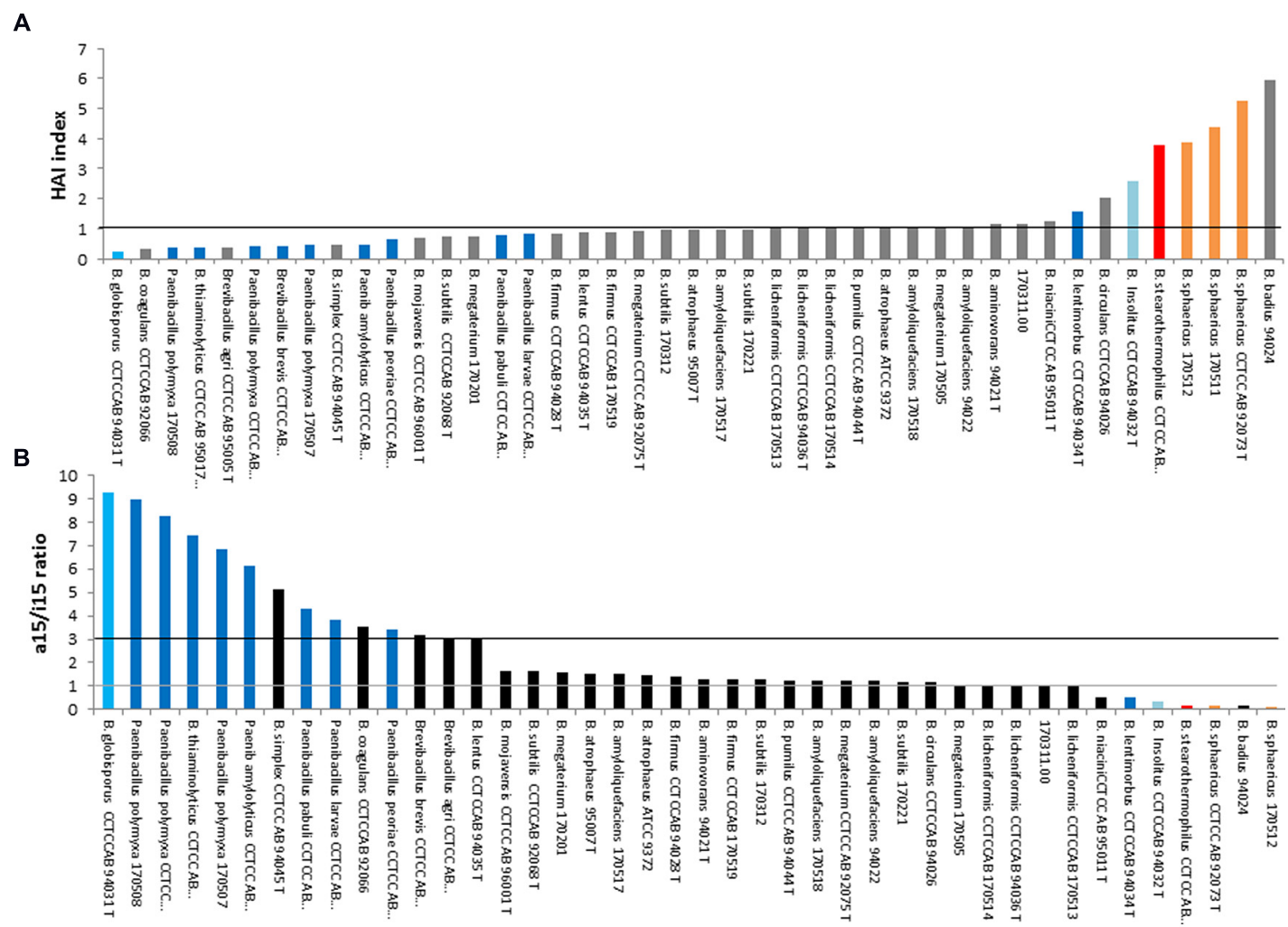

FIGURE 5 | Heat adaptation index (A) and a15/i15 ratio (B) among strains of the genus Bacillus, excluding Bacillus cereus sensu lato. The strains displaying values close to the black line $\mathbf{( A )}$ or between the gray line and the black line (B) are mesophilic strains. Reclassified species are: Sporosarcina (blue), Peanibacillus (dark blue), Geobacillus (red), Lysinibacillus (orange), Psychrobacillus (pale blue). Gray (A) or black (B): Bacillus strains.
Uetanabaro et al., 2003; Vos et al., 2011). Some of these genera are represented in Figure 5 (Paenibacillus, Sporosarcina, Geobacillus, Lysinibacillus, Psychrobacillus). This could have contributed to separate entities with different thermotypes. For example, Paenibacillus genus originating from mesophilic Bacillus is known to contain mesophilic species mostly characterized by psychrotrophic abilities (Ivy et al., 2012). The data used here come from a study performed before most of these rearrangements, thus some may contain incoherencies.

(iii) As for B. cereus sl strains, some species (e.g., B. coagulans or B. sphaericus) may display a FA profile with major FAs different compared to the other Bacillus strains (with i17:0/a17:0 or i16/i16 among major FAs) and were thus difficult to be characterized by a15/i15 ratio and HAI index.

Regardless of the method used, it appears important that the group of strain studied displays at least the same type of dominant FAs (branched-chain C15 FAs) to avoid a biased analysis. Indeed, the FA profiles of some Bacillus species or related genera are so different that it can lead to the inappropriate determination of thermotype for the strains (i.e., B. cereus sl, B. coagulans, Lysinibacillus, Psychrobacillus).

The observation that a15:0 and i15:0 are also present in HAI and that the two methods resulted in the same global results may indicate that the other FAs utilized in HAI have a minor role in the thermotype determination.

\section{Perspectives in this Field}

In conclusion, the a15/i15 ratio for several Bacillus and related genera and the $\mathrm{i} 15 / \mathrm{i} 13$ ratio and $\mathrm{C} 16: 1$ (5) proportion for $B$. cereus $s l$ species may be good indicators of temperature adaptation but need to be further evaluated. Since 2010, taxonomists imposed the description of the FA profile for all newly described species. More accurate data on a wider range of well delimited species and representative strains of Bacillus should strengthen the proposed link between the FA profile of a strain/species and its thermotype.

\section{Changes in FA Composition During Bacillus Adaptation}

\section{Changes Depending on Food Components and the Growth Medium Composition}

The growth medium (including food) may also influence the FA composition of several strains of the Bacillus genus. For instance, UFAs from spinach or from a growth medium supplemented with lecithin have been detected in the membrane FAs of $B$. cereus (De Sarrau et al., 2013), leading to an increase in membrane fluidity, improved growth at low temperatures and anaerobiosis. 
Strains of B. cereus isolated from rice were also tested for their growth ability at reduced temperatures and reduced water activity in rice starch (Haque and Russell, 2004). Rice starch stimulated the growth of the tested strains and modified the FA composition by increasing the proportion of branched-chain FAs and the ratio of iso/anteiso. In contrast to spinach (De Sarrau et al., 2013), UFAs from rice were not detected in $B$. cereus FAs (Haque and Russell, 2004).

When the growth of $B$. thuringiensis was performed in the presence of compounds that are specific precursors for branchedchain FA biosynthesis, such as butyrate, isobutyrate, valerate, and isovalerate, an increase in branched-chain FAs was observed in spores (Nickerson and Bulla, 1980).

In $B$. subtilis, the presence of isoleucine versus leucine, or of the respectively derived anteiso branched-chain FA precursors in the growth medium, increased the proportion of anteiso versus iso branched-chain FAs (Cybulski et al., 2002). In addition, the presence of isoleucine reduced the proportion of UFAs.

Ehrhardt et al. (2010) found that the FA composition of $B$. cereus spores was specific to the growth medium, with important variations in the proportions of $\mathrm{i} 13, \mathrm{i} 15, \mathrm{n} 16$, and C18:1 FAs and of total branched FAs.

\section{Changes Depending on the Temperature}

The effect of temperature on the FA composition of Bacillus has been studied for years (Fulco, 1967). When confronted with a change in temperature, the species in the Bacillus genus modify their FA composition (Aguilar et al., 2001; Haque and Russell, 2004). These changes often involve branched-chain and unsaturated FAs.

When the temperature was raised to 60,70 , or $80^{\circ} \mathrm{C}$, an increase in the iso-branched-chain FA iso-C17 and the linear C16:0 FA was observed in thermophilic species such as B. caldolyticus and B. caldotenax (Weerkamp and Heinen, 1972). In $B$. simplex strains grown at a high temperature $\left(40^{\circ} \mathrm{C}\right)$, the isobranched FA proportion increased, whereas the anteiso-branched and unsaturated FA proportions decreased (Sikorski et al., 2008).

Decreasing the growth temperature of some Bacillus genus species induced an increase in monounsaturated FAs and a decrease in saturated straight chain FAs. In addition to these changes, the proportion of branched-chain FAs (whether iso or anteiso-branched-chain FAs) increased with a decreasing temperature (Freese et al., 2008).

Similarly, an increased proportion of unsaturated FAs, but only of anteiso-branched-chain FAs, was observed in B. simplex strains isolated from specific habitats of a Canyon in Israel when grown at a low temperature $\left(20^{\circ} \mathrm{C}\right)$ (Sikorski et al., 2008). A significant decrease in the relative concentration of all of the unbranched or iso-branched FAs was also observed. Reciprocally, at a high temperature $\left(40^{\circ} \mathrm{C}\right)$, the proportion of iso-branched FAs increased, whereas the proportions of anteiso-branched and unsaturated FAs decreased (Sikorski et al., 2008).

Studies investigating B. subtilis and B. cereus adaptation to low temperature have underscored the key role played by UFAs (Aguilar et al., 2001) in the homeostasis of membrane fluidity at reduced temperatures (Haque and Russell, 2004; Brillard et al., 2010; Chazarreta Cifre et al., 2013). UFAs produced by $\Delta 5$-desaturase activity are specifically important for low temperature adaptation (Kaneda, 1972; Lombardi and Fulco, 1980; Mansilla et al., 2003). Some species such as B. cereus also possess a $\Delta 10$ desaturase that inserts a cis-double bond at the $\Delta 10$ position of the acyl chains of membrane phospholipids but is active regardless of the growth temperature (Chazarreta Cifre et al., 2013).

Some species in the Bacillus genus are facultative anaerobes (Rosenfeld et al., 2005; Yu et al., 2013; Tang et al., 2014). Under anaerobic conditions, $B$. subtilis and $B$. cereus, and presumably other Bacillus species that are devoid of FabA and FabB, are no longer able to synthesize UFAs. Thus, in the absence of oxygen (anaerobic respiration of nitrates), conditions in which FA desaturation by $B$. subtilis is not possible, the anteiso/iso ratio increased at low temperatures, leading to a concomitant increase in membrane fluidity (Beranova et al., 2010). More generally, even under aerobic conditions, in the presence of isoleucine, the expression of the FA desaturase gene des decreased at optimal and cold temperatures in B. subtilis (Cybulski et al., 2002). It is likely that the main mechanism utilized in B. subtilis to maintain membrane fluidity homeostasis is the synthesis of anteiso branched FAs. This does not appear to be the case for $B$. cereus, in which low temperature induces an increase in UFAs (mostly in the $\Delta 5$ position) but not in anteiso branched-chain FAs, even in media containing isoleucine (Brillard et al., 2010; De Sarrau et al., 2012).

In $B$. cereus, the $i 15 / 13$ ratio decreased markedly at low temperatures (Diomandé et al., 2015b). In a lipase mutant of $B$. cereus, in which the i15/i13 ratio was much higher than that in the parental strain, growth impairment at low temperature was observed, emphasizing the probable role of a low i15/i13 ratio in psychrotolerance ability (Brillard et al., 2010). This result is consistent with the observation that this ratio is lower in psychrotrophic strains of $B$. cereus sl. (see the specific case of Bacillus cereus sensu lato). Such changes in the i15/i13 ratio have not been reported for other Bacillus species.

In conclusion, the main changes observed in the FA composition of the genus Bacillus at low and high temperatures are presented in Figure 6. For low temperature adaptation, anteiso-, unsaturated FAs and 113 proportions increased, while iso-, saturated FAs and i15 proportions decreased. In contrast, the proportion of saturated FAs increased, and the proportions of anteiso and unsaturated FAs decreased at high temperature. The respective importance of these mechanisms may change with the species considered and the growth conditions.

\section{Changes Induced by other Conditions}

Several other abiotic factors are known to induce modifications in the FA composition of Bacillus species.

When comparing the FA profile of $B$. alkaliphilic grown at $\mathrm{pH}$ 10 , the proportion of UFAs and the anteiso/iso branched-chain FA ratio were lower when compared with the species grown at pH 7 (Yumoto et al., 2000). Similarly, for B. subtilis cells grown at pH 8.5 (Petrackova et al., 2010), the anteiso/iso branchedchain FA ratio and the total proportion of branched-chain FAs decreased compared with $\mathrm{pH}$ 7. These authors found the same trend, but with wider variations in cells grown at $\mathrm{pH} 5$ compared 


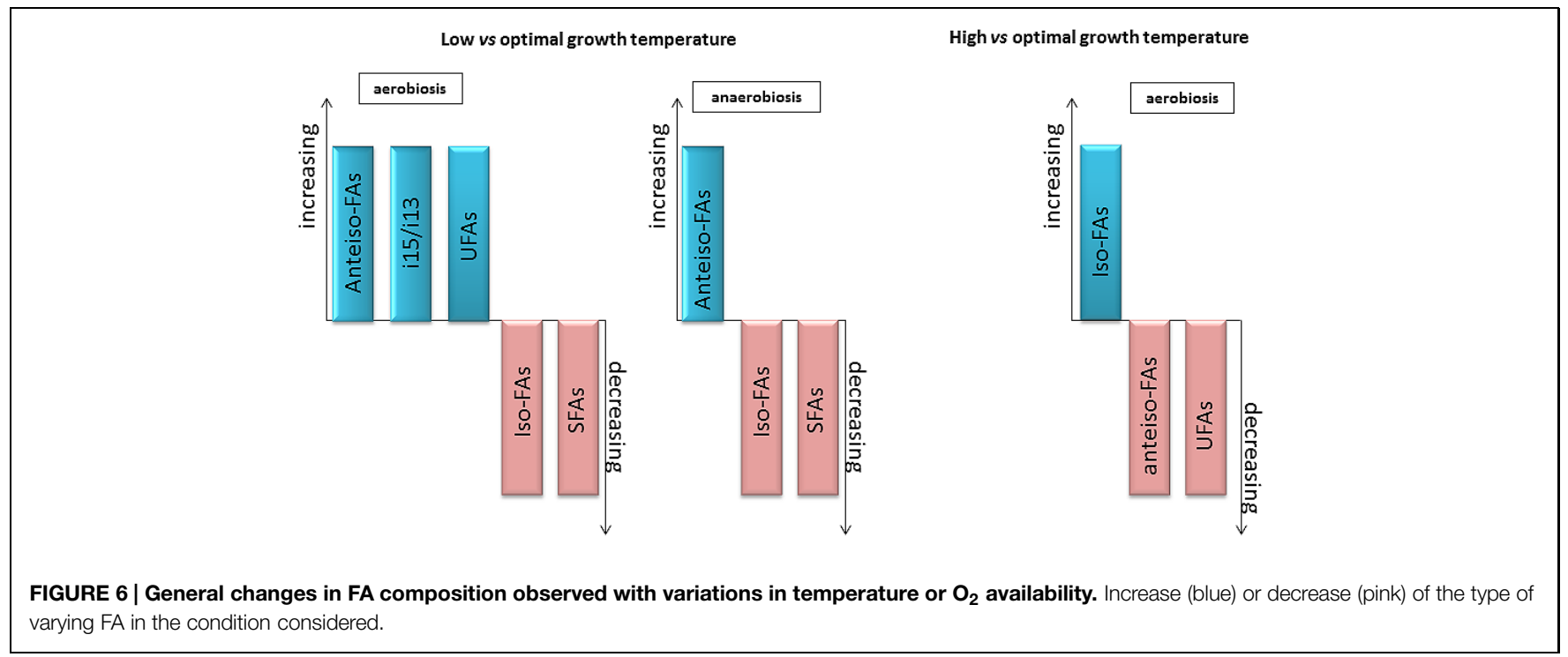

with those grown at $\mathrm{pH} 7$, resulting in more rigid membranes. In six different species of Bacillus, survival at a low $\mathrm{pH}$ (from 5 to 2) induced a global decrease in odd FAs, which are mostly branchedchain FAs in Bacillus (Shobharani and Halami, 2014), indicating that this may be a general adaptation to low $\mathrm{pH}$ among Bacillus. Moreover, a transcriptomic analysis during sorbic acid stress in B. subtilis revealed that genes important for FA biosynthesis were up-regulated, supporting the occurrence of plasma membrane remodeling in the stressed cells (Ter Beek et al., 2008). It was difficult to determine the FA modifications induced in B. cereus by reduced water activity because they depended on the solute used (sodium chloride versus sucrose) as well as on the strain (Haque and Russell, 2004).

Gamma irradiation treatment also induces changes in FA composition in some Bacillus species. In B. cereus, this treatment increases the proportion of UFAs (Ayari et al., 2009).

Low pressure is another influential factor: B. subtilis cells grown at 50 versus 1013 mbar show an increase in the ratio of unsaturated to saturated FAs but a decrease in the ratio of anteisoto iso-FAs (Fajardo-Cavazos et al., 2012).

Some nanoparticles may be toxic for bacteria (Zhu et al., 2014). When B. subtilis was exposed to carbon nanotubes, an increased proportion of branched-chain FAs and a decreased amount of straight-chain FAs were observed (Zhu et al., 2014).

Thus, when facing various stressful environmental conditions such as those described above, Bacillus species alter their FA composition by increasing or decreasing the proportion of FAs with lower melting points, depending on the stress applied.

\section{Production of Bioactive FA-Derivatives}

Under specific conditions, such as in response to the presence of some fungi (Li et al., 2014), colonization of the rhizosphere (Nihorimbere et al., 2009), biofilm formation (Hofemeister et al., 2004), or spreading to colonize a substrate (Angelini et al., 2009), some Bacillus species synthesize special FAs that are not integrated in their membrane but are components of excreted lipopeptides. These molecules display a wide range of bioactive properties, such as active surface properties and biocide capacity, and they play a key role in the adaptation of this Bacillus to various environments. For example, surfactin is a cyclic lipoheptapeptide that contains a $\beta$-hydroxy FA but no di-sulfide bridges or sugar residues. This molecule, which is produced by B. subtilis subsp. subtilis and B. licheniformis, possesses antimicrobial properties (Compaore et al., 2013).

Bacillus amyloliquefaciens is able to synthesize 26 types of surfactin, which act as potential antifungal metabolites. Among these, several new cyclic as well as acyclic surfactin variants have been identified based on the variation in the $\beta$-hydroxy fatty acid $(\beta-\mathrm{OH} \mathrm{FA})$ chain length and/or in amino acid positions $4,5,6$, and 7 (Pathak et al., 2014). Other surfactins, such as those with long FA chains (C14 and $\mathrm{C} 15)$ and characterized in B. subtilis (S499 strain), have insecticide effects on the fruit fly Drosophila melanogaster (Assie et al., 2002).

\section{Changes Depending on the Bacterial Cell State}

The sporulation and germination of Bacillus species may also induce changes in the FA pattern. Indeed, it has been shown that de novo FA synthesis is required to establish cell type-specific gene transcription during sporulation in B. subtilis (Schujman et al., 1998).

In a study of $\sim 50$ different species of Bacillus genus, the FA content of spores and cells were very similar (Song et al., 2000), but the proportion of branched-chain FAs (and more specifically, i15:0, the a15:0 and i17:0) was elevated in spores compared with vegetative cells. Moreover, some FAs present in vegetative cells were only detected at trace levels in spores (e.g., 3OH-C14:0 acid,

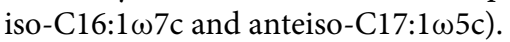

In $B$. megaterium, sporulation induced the synthesis of i14:0 branched-chain FAs in addition to the major FA i15:0 and, consequently, an increase in the proportion of branched-chain FAs was observed in the spores (Scandella and Kornberg, 1969). When the spores germinated, the proportion of branched-chain FAs returned to that observed in vegetative cells (Scandella and Kornberg, 1969). 
In $B$. weihenstephanensis, spores obtained at $30^{\circ} \mathrm{C}$ displayed almost the same profile as vegetative cells, but during sporulation at $10^{\circ} \mathrm{C}$, they displayed a different pattern (Planchon et al., 2011). In particular, the cold induced an increase in anteiso-branchedchain FAs but not UFAs, as observed in vegetative cells.

\section{Exogenous FAs: their Impact on Bacillus Growth}

Fatty acids can be used as antimicrobials as a result of two main particularities: their lipophilicity and their acidity. To better understand the anti-microbial ability of exogenous FAs, several investigations have been performed, mostly in the food industry, which often aims to produce minimally processed food that is preserved against pathogens. Some examples are discussed below.

\section{Inhibition of Spore Germination}

An antimicrobial activity of exogenous FAs resides in their capacity to inhibit spore germination and/or outgrowth. Indeed, in the presence of lauric acid (12C) and oleic acid (18C), $B$. cereus spore germination is completely inhibited (Ababouch et al., 1994). The authors hypothesized that this phenomenon resulted from the inhibition of germinant binding to germination sites. This inhibition was reversible because no additional inhibition was observed when the medium was depleted of these FAs.

Moreover, even in fully germinated spores, an inhibition of outgrowth was observed in the presence of lauric acid and two polyunsaturated FAs with 18C: linoleic and linolenic acids (Ababouch et al., 1994). The underlying mechanisms depended on the type of FAs, but the inner membrane of the germinated spores was shown to be the site of action of these inhibitors. Sorbic acid, a short UFA, has also been shown to delay the germination and outgrowth of B. cereus spores (Van Melis et al.,
2011) as well as to inhibit spore germination (Smoot and Pierson, 1981).

Some FAs, such as laurate, palmitate, stearate and/or some FA esters, inhibit Bacillus spores in various culture conditions characterized by different temperatures, pressure and in combination with other chemical compounds such as sucrose or monoglycerol (Feijoo et al., 1997; Shearer et al., 2000; Klangpetch et al., 2013). However, for most of the cases cited above, an inhibitory rather than a lethal effect on the Bacillus spores was observed.

However, studies have also described the FAs, more specifically the UFAs, in terms of their ability to markedly decrease bacterial spore heat resistance, leading to a lethal effect on spores. A model has been used to describe the decrease in D-values (time for a $\log _{10}$ population decrease) in the presence of free FAs during low sterilization treatment (Lekogo et al., 2010).

\section{Growth Inhibition}

Exogenous FAs may also inhibit the growth of vegetative cells. Linolenic acid, free or in addition to monoglyceride, displays strong antimicrobial activity against $B$. cereus cells (Lee et al., 2002). The addition of linolenic acid to medium was accompanied by a drastic increase in the bacterial extracellular ATP concentration and a decrease in the intracellular ATP concentration (Lee et al., 2002). Palmitic and stearic acid from clove oil also inhibited the growth of a range of microorganisms including B. subtilis (Assiri and Hassanien, 2013).

The presence of oleic acid markedly reduced the resistance of the protonophore-resistant strain C8 of $B$. megaterium to low concentrations of the carbonylcyanide $\mathrm{m}$-chlorophenylhydrazone (CCCP) protonophore (Clejan et al., 1988). This loss of resistance was explained by the higher level of UFAs in the membrane of this bacterium when grown in presence of oleic acid. Conversely, the growth of the CCCPsensitive wild-type strain in the presence of a saturated FA (stearic acid) improved resistance against the protonophore

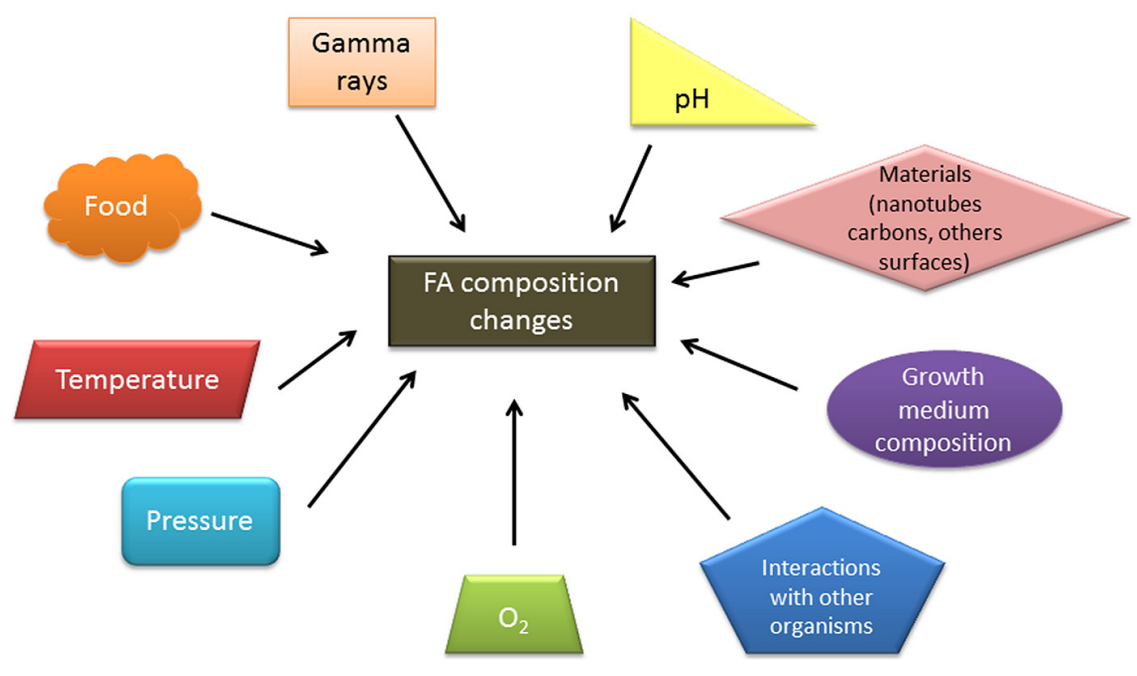

FIGURE 7 | Environmental factors influencing the FA composition of Bacillus genus strains. 
by increasing the saturated/unsaturated FA ratio (Clejan et al., 1988).

Thus, the effect of a given FA on growth appears to depend on both its properties and the environmental conditions.

\section{Improved Growth}

In contrast, exogenous FAs may function as growth activators for vegetative Bacillus cells under particular conditions. As described above, B. megaterium can incorporate free FAs from the medium, and a modulation of resistance to the protonophores may be observed depending on the FA. Stearic acid (Clejan et al., 1988) in B. megaterium and palmitic acid in B. subtilis (Krulwich et al., 1987) are saturated FAs that are able to improve resistance against the protonophore.

Bacillus cereus can use exogenous phospholipids and integrate the FAs present in these phospholipids into its membrane (De Sarrau et al., 2013). For example, at low temperatures under anaerobiosis, the growth of $B$. cereus strains is presumably inhibited because membrane lipids and fluidity cannot adapt to low temperatures without oxygen (De Sarrau et al., 2012). UFAs from food (spinach) or from the bacterial medium can be incorporated into the membrane to facilitate the adaptation of strains grown at low temperature under anaerobiosis. Indeed, under this condition and in the presence of UFA precursors, the growth of these strains is similar to that under aerobiosis at low temperatures (De Sarrau et al., 2013).

In $B$. cereus, an exogenous source of UFAs was shown to improve the growth of the cas $K / R$ mutant (Diomandé et al., 2015a). This mutant displayed a decreased proportion of UFAs during growth at low temperatures compared to the parental strain, and an exogenous source of UFAs provided support to membrane-level modifications caused by the mutation.

Finally, some species, such as B. megaterium, may grow in medium supplemented with exogenous FAs, oxidize them and produce polyunsaturated FAs that are important industrial materials for the manufacture of valuable products such as oxygenated oils (Hou, 2009).

\section{Conclusion}

Fatty acids are a universal pillar component of cellular membranes. FAs have been studied extensively in Bacillus species, and their involvement in a wide variety of adaptations highlights their predominant role in survival, growth and spore formation. In Bacillus species, FAs represent a good biomarker to determine the exact repartition among Bacillus species, depending on their environmental niche. At the metabolic level, FAS II is connected to major cell metabolic pathways, and FAs synthesis appears to be finely regulated depending on the needs of the cell. Numerous regulators control FA metabolism, and the regulation is clearly dependent on the environmental conditions of the cell.

Depending on the environment, Bacillus species can display different FA patterns, which are mainly related to adaptation and survival (Figure 7). This ability to easily change their FAs profiles may contribute to the ubiquity of these species. Even if the FA composition varies in response to environmental fluctuations, some features of the FA pattern are conserved, which sometimes correlates to the growth ability of the species in a given environmental niche. Therefore, it is important to distinguish the short-term (short-time adaptation) from the longterm (long-term adaptation) change in FA composition during the evolution of a species. The impact of the observed changes in FA composition during the short-term adaptation of a species with different ecological abilities on membranes properties (e.g., fluidity, permeability) has seldom been measured, limiting the interpretation of their importance. There are some common features between the short-term and long-term adaptation of a species to temperature. In species grown at their lowest growth temperature domain versus their optimal temperature, and also in cold-adapted species grown at an optimal temperature versus mesophilic or thermotolerant species, a higher proportion of some UFAs and/or a higher ratio of anteiso/iso branched-chain FAs has been observed; both changes increase the membrane fluidity. These two main mechanisms do not seem to occur in $B$. cereus species, which display no clear changes in the anteiso/iso ratio, either during short-term adaptation to changes in temperature or long-term evolution of the phylogenetic groups within $B$. cereus. The impact of other changes on the membrane properties in relation to long-term and short-term adaptation to temperature, such as the i13/i15 ratio in B. cereus, remains unknown. It is possible that this change in the chain length of major FAs modifies the membrane fluidity. In contrast to temperature, there is no clear understanding of the role of FAs in the short-term and long-term adaptation to other environmental conditions (e.g., water activity, $\mathrm{pH}$ ).

Some precautions should be taken because changes in FAs during short-term adaptation may lead to biases during the identification of strains. Therefore, it is important to combine genetic comparisons with the FA pattern and define optimal growth parameters for the newly described strain before assigning the genus and/or species affiliation.

Bacillus strains are also able to use FAs from their environment, including from food. This phenomenon is consistent with the observation that some Bacillus strains represent a major cause of foodborne illness. However, the impact of the use of these exogenous FAs may be positive or negative depending on the Bacillus cell state (spores or vegetative cells), the source of the FAs (e.g., free FAs or lipids), and/or the type of FAs, and it appears to depend on the environmental conditions. The antimicrobial activity of some of these exogenous FAs might be effective for food preservation during processing and for the conservation of food.

Altogether, the relationship between the bacterial FA composition and the physiological impact under environmental stresses might be the timely suitable and important issue to be further investigated in detail.

\section{Author Contributions}

$\mathrm{SD}$ analyzed the data from the literature and organized and wrote the manuscript. CN-T analyzed the data and was involved 
in writing the final version of the manuscript. M-HG and VB analyzed the data and edited the manuscript. JB analyzed the data and was involved in writing the different versions of the manuscript. All of the authors read and approved the final version of the manuscript.

\section{References}

Ababouch, L. H., Bouquartacha, F., and Busta, F. F. (1994). Inhibition of l-alanine triggered Bacillus cereus $T$ spore germination and outgrowth by fatty acids and glyceryl monododecanoate. Food Microbiol. 11, 385-396. doi: 10.1006/fmic.1994.1037

Abis [ABIS v.9]. (n.d.). Online Encyclopedia [Online]. Available at: http://www. tgw1916.net/Bacillus.html [Accessed December 1, 2014].

Aguilar, P. S., Cronan, J. E. Jr., and De Mendoza, D. (1998). A Bacillus subtilis gene induced by cold shock encodes a membrane phospholipid desaturase. J. Bacteriol. 180, 2194-2200.

Aguilar, P. S., Hernandez-Arriaga, A. M., Cybulski, L. E., Erazo, A. C., and De Mendoza, D. (2001). Molecular basis of thermosensing: a two-component signal transduction thermometer in Bacillus subtilis. EMBO J. 20, 1681-1691. doi: 10.1093/emboj/20.7.1681

Ahmed, I., Yokota, A., Yamazoe, A., and Fujiwara, T. (2007). Proposal of Lysinibacillus boronitolerans gen. nov. sp. nov., and transfer of Bacillus fusiformis to Lysinibacillus fusiformis comb. nov. and Bacillus sphaericus to Lysinibacillus sphaericus comb. nov. Int. J. Syst. Evol. Microbiol. 57, 1117-1125. doi: 10.1099/ijs.0.63867-0

Angelini, T. E., Roper, M., Kolter, R., Weitz, D. A., and Brenner, M. P. (2009). Bacillus subtilis spreads by surfing on waves of surfactant. Proc. Natl. Acad. Sci. U.S.A. 106, 18109-18113. doi: 10.1073/pnas.0905890106

Assie, L. K., Deleu, M., Arnaud, L., Paquot, M., Thonart, P., Gaspar, C., et al. (2002). Insecticide activity of surfactins and iturins from a biopesticide Bacillus subtilis Cohn (S499 strain). Meded. Rijksuniv. Gent. Fak. Landbouwkd. Toegep. Biol. Wet. 67, 647-655.

Assiri, A. M., and Hassanien, M. F. (2013). Bioactive lipids, radical scavenging potential, and antimicrobial properties of cold pressed clove (Syzygium aromaticum) oil. J. Med. Food 16, 1046-1056. doi: 10.1089/jmf.2012.0288

Ayari, S., Dussault, D., Millette, M., Hamdi, M., and Lacroix, M. (2009). Changes in membrane fatty acids and murein composition of Bacillus cereus and Salmonella Typhi induced by gamma irradiation treatment. Int. J. Food Microbiol. 135, 1-6. doi: 10.1016/j.ijfoodmicro.2009.07.012

Baindara, P., Mandal, S. M., Chawla, N., Singh, P. K., Pinnaka, A. K., and Korpole, S. (2013). Characterization of two antimicrobial peptides produced by a halotolerant Bacillus subtilis strain SK.DU.4 isolated from a rhizosphere soil sample. AMB Express 3, 2. doi: 10.1186/2191-0855-3-2

Barabesi, C., Galizzi, A., Mastromei, G., Rossi, M., Tamburini, E., and Perito, B. (2007). Bacillus subtilis gene cluster involved in calcium carbonate biomineralization. J. Bacteriol. 189, 228-235. doi: 10.1128/JB.01450-06

Bartoszewicz, M., Kroten, M. A., and Swiecicka, I. (2013). Germination and proliferation of emetic Bacillus cereus sensu lato strains in milk. Folia Microbiol. 58, 529-535. doi: 10.1007/s12223-013-0237-7

Beaman, T. C., Pankratz, H. S., and Gerhardt, P. (1974). Chemical composition and ultrastructure of native and reaggregated membranes from protoplasts of Bacillus cereus. J. Bacteriol. 117, 1335-1340.

Beijer, L., Nilsson, R. P., Holmberg, C., and Rutberg, L. (1993). The $g l p P$ and $g l p F$ genes of the glycerol regulon in Bacillus subtilis. J. Gen. Microbiol. 139, 349-359. doi: 10.1099/00221287-139-2-349

Beranova, J., Mansilla, M. C., De Mendoza, D., Elhottova, D., and Konopasek, I. (2010). Differences in cold adaptation of Bacillus subtilis under anaerobic and aerobic conditions. J. Bacteriol. 192, 4164-4171. doi: 10.1128/JB.00384-10

Berkeley, R., Heyndrickx, M., Logan, N., and De Vos, P. (2002). Applications and Systematics of Bacillus and Relatives. Oxford: Blackwell Science Ltd.

Bishop, D. G., Rutberg, L., and Samuelsson, B. (1967). The Chemical Composition of the Cytoplasmic Membrane of Bacillus subtilis. Eur. J. Biochem. 2, 448-453. doi: 10.1111/j.1432-1033.1967.tb00158.x

Boudreaux, D. P., Eisenstadt, E., Iijima, T., and Freese, E. (1981). Biochemical and genetic characterization of an auxotroph of Bacillus subtilis altered in the

\section{Acknowledgments}

The authors thank the INRA-MICA department and the Provence Alpes-Côte d'Azur Regional Council for providing financial support for SD's Ph.D.

Acyl-CoA:acyl-carrier-protein transacylase. Eur. J. Biochem. 115, 175-181. doi: 10.1111/j.1432-1033.1981.tb06214.x

Bredeston, L. M., Marciano, D., Albanesi, D., De Mendoza, D., and Delfino, J. M. (2011). Thermal regulation of membrane lipid fluidity by a twocomponent system in Bacillus subtilis. Biochem. Mol. Biol. Educ. 39, 362-366. doi: 10.1002/bmb.20510

Brillard, J., Jehanno, I., Dargaignaratz, C., Barbosa, I., Ginies, C., Carlin, F., et al. (2010). Identification of Bacillus cereus genes specifically expressed during growth at low temperatures. Appl. Environ. Microbiol. 76, 2562-2573. doi: 10.1128/AEM.02348-09

Brinsmade, S. R., Kleijn, R. J., Sauer, U., and Sonenshein, A. L. (2010). Regulation of CodY activity through modulation of intracellular branched-chain amino acid pools. J. Bacteriol. 192, 6357-6368. doi: 10.1128/JB.00937-10

Celik, A., Sperandio, D., Speight, R. E., and Turner, N. J. (2005). Enantioselective epoxidation of linolenic acid catalysed by cytochrome P450BM3 from Bacillus megaterium. Org. Biomol. Chem. 3, 2688-2690. doi: 10.1039/b506155e

Chan, M., Himes, R. H., and Akagi, J. M. (1971). Fatty acid composition of thermophilic, mesophilic, and psychrophilic Clostridia. J. Bacteriol. 106, 876-881.

Chazarreta Cifre, L., Alemany, M., De Mendoza, D., and Altabe, S. (2013). Exploring the biosynthesis of unsaturated fatty acids in Bacillus cereus ATCC 14579 and functional characterization of novel acyl-lipid desaturases. Appl. Environ. Microbiol. 79, 6271-6279. doi: 10.1128/AEM.01761-13

Chazarreta-Cifre, L., Martiarena, L., De Mendoza, D., and Altabe, S. G. (2011). Role of ferredoxin and flavodoxins in Bacillus subtilis fatty acid desaturation. J. Bacteriol. 193, 4043-4048. doi: 10.1128/JB.05103-11

Cherniavskaia, E. N., and Vasiurenko, Z. P. (1983). [Fatty acid composition of the lipopolysaccharides of bacteria in the genera Escherichia, Shigella and Salmonella as a taxonomic trait]. Zh. Mikrobiol. Epidemiol. Immunobiol. 7, 35-38.

Chirala, S. S., Huang, W.-Y., Jayakumar, A., Sakai, K., and Wakil, S. J. (1997). Animal fatty acid synthase: Functional mapping and cloning and expression of the domain I constituent activities. Proc. Natl. Acad. Sci. 94, 5588-5593. doi: 10.1073/pnas.94.11.5588

Cho, K. Y., and Salton, M. R. J. (1966). Fatty acid composition of bacterial membrane and wall lipids. Biochim. Biophys. Acta 116, 73-79. doi: 10.1016/0005-2760(66)90093-2

Choi, J. H., and Cha, C. J. (2014). Bacillus panacisoli sp. nov., isolated from ginseng soil. Int. J. Syst. Evol. Microbiol. 64, 901-906. doi: 10.1099/ijs.0.054320-0

Choi, K. H., Heath, R. J., and Rock, C. O. (2000). beta-ketoacyl-acyl carrier protein synthase III $(\mathrm{FabH})$ is a determining factor in branched-chain fatty acid biosynthesis. J. Bacteriol. 182, 365-370. doi: 10.1128/JB.182.2.365370.2000

Clejan, S., Guffanti, A. A., Falk, L. H., and Krulwich, T. A. (1988). The protonophore resistance of Bacillus megaterium is correlated with elevated ratios of saturated to unsaturated fatty acids in membrane phospholipids. Biochim. Biophys. Acta 932, 43-51. doi: 10.1016/0005-2728(88)90138-7

Comella, N., and Grossman, A. D. (2005). Conservation of genes and processes controlled by the quorum response in bacteria: characterization of genes controlled by the quorum-sensing transcription factor ComA in Bacillus subtilis. Mol. Microbiol. 57, 1159-1174. doi: 10.1111/j.1365-2958.2005. 04749.x

Compaore, C. S., Nielsen, D. S., Ouoba, L. I., Berner, T. S., Nielsen, K. F., SawadogoLingani, H., et al. (2013). Co-production of surfactin and a novel bacteriocin by Bacillus subtilis subsp. subtilis $\mathrm{H} 4$ isolated from Bikalga, an African alkaline Hibiscus sabdariffa seed fermented condiment. Int. J. Food. Microbiol. 162, 297-307. doi: 10.1016/j.ijfoodmicro.2013.01.013

Connor, N., Sikorski, J., Rooney, A. P., Kopac, S., Koeppel, A. F., Burger, A., et al (2010). Ecology of speciation in the genus Bacillus. Appl. Environ. Microbiol. 76, 1349-1358. doi: 10.1128/AEM.01988-09 
Cronan, J. E. Jr., and Bell, R. M. (1974). Mutants of Escherichia coli defective in membrane phospholipid synthesis: mapping of the structural gene for L-glycerol 3-phosphate dehydrogenase. J. Bacteriol. 118, 598-605.

Cronan, J. E., and Vagelos, P. R. (1972). Metabolism and function of the membrane phospholipids of Escherichia coli. Biochim. Biophys. Acta 265, 25-60. doi: 10.1016/0304-4157(72)90018-4

Cybulski, L. E., Albanesi, D., Mansilla, M. C., Altabe, S., Aguilar, P. S., and De Mendoza, D. (2002). Mechanism of membrane fluidity optimization: isothermal control of the Bacillus subtilis acyl-lipid desaturase. Mol. Microbiol. 45, 1379-1388. doi: 10.1046/j.1365-2958.2002.03103.x

Cybulski, L. E., Martin, M., Mansilla, M. C., Fernandez, A., and De Mendoza, D. (2010). Membrane thickness cue for cold sensing in a bacterium. Curr. Biol. 20, 1539-1544. doi: 10.1016/j.cub.2010.06.074

Da Costa, M. F., Rainey, F. A., and Albuquerque, L. (2009). "Genus Alicyclobacillus," in Bergey's Manual of Systematic Bacteriology, 2nd Edn, The Firmicultes, eds P. De Vos, G. M. Garrity, D. Jones, N. R. Krieg, W. Ludwig, F. A. Rainey, et al. (New York, NY: Springer-Verlag), 229-243.

De La Fuente-Salcido, N. M., Casados-Vazquez, L. E., and Barboza-Corona, J. E. (2013). Bacteriocins of Bacillus thuringiensis can expand the potential of this bacterium to other areas rather than limit its use only as microbial insecticide. Can. J. Microbiol. 59, 515-522. doi: 10.1139/cjm-2013-0284

De Sarrau, B., Clavel, T., Clerte, C., Carlin, F., Ginies, C., and Nguyen-The, C. (2012). Influence of anaerobiosis and low temperature on Bacillus cereus growth, metabolism, and membrane properties. Appl. Environ. Microbiol. 78, 1715-1723. doi: 10.1128/AEM.06410-11

De Sarrau, B., Clavel, T., Zwickel, N., Despres, J., Dupont, S., Beney, L., et al. (2013). Unsaturated fatty acids from food and in the growth medium improve growth of Bacillus cereus under cold and anaerobic conditions. Food Microbiol. 36, 113-122. doi: 10.1016/j.fm.2013.04.008

Debarbouille, M., Gardan, R., Arnaud, M., and Rapoport, G. (1999). Role of $\mathrm{BkdR}$, a transcriptional activator of the SigL-dependent isoleucine and valine degradation pathway in Bacillus subtilis. J. Bacteriol. 181, 2059-2066.

Diomandé, S., Chamot, S., Antolinos, V., Vasai, F., Guinebretière, M.-H., Bornard, I., et al. (2014). The CasKR two-component system is required for growth at low temperature of mesophilic and psychrotolerant Bacillus cereus strains. Appl. Environ. Microbiol. 80, 2493-2503. doi: 10.1128/AEM.00090-14

Diomandé, S., Nguyen-The, C., Abee, T., Tempelaars, M. H., Broussolle, V., and Brillard, J. (2015a). Involvement of the CasK/R two-component system in optimal unsaturation of the Bacillus cereus fatty acids during low-temperature growth. Int. J. Food Microbiol. doi: 10.1016/j.ijfoodmicro.2015.04.043 [Epub ahead of print].

Diomandé, S., Guinebretiere, M., De Sarrau, B., Nguyen-The, C., Broussolle, V., and Brillard, J. (2015b). Fatty acid profiles and desaturase-encoding genes are different in thermo- and psychrotolerant strains of the Bacillus cereus Group. BMC Res. (in press). doi: 10.1186/s13104-015-1288-4

Dirusso, C. C., and Black, P. N. (2004). Bacterial long chain fatty acid transport: gateway to a fatty acid-responsive signaling system. J. Biol. Chem. 279, 4956349566. doi: 10.1074/jbc.R400026200

Ehrhardt, C. J., Chu, V., Brown, T., Simmons, T. L., Swan, B. K., Bannan, J., et al. (2010). Use of fatty acid methyl ester profiles for discrimination of Bacillus cereus T-strain spores grown on different media. Appl. Environ. Microbiol. 76, 1902-1912. doi: 10.1128/AEM.02443-09

Esser, A. F., and Souza, K. A. (1974). Correlation between thermal death and membrane fluidity in Bacillus stearothermophilus. Proc. Natl. Acad. Sci. U.S.A. 71, 4111-4115. doi: 10.1073/pnas.71.10.4111

Euzeby, J. (2015). List of Prokaryotic Names with Standing in Nomenclature [Online]. Available: http://www.bacterio.net/ [Accessed May 13, 2015].

Fajardo-Cavazos, P., Waters, S. M., Schuerger, A. C., George, S., Marois, J. J., and Nicholson, W. L. (2012). Evolution of Bacillus subtilis to enhanced growth at low pressure: up-regulated transcription of des-desKR, encoding the fatty acid desaturase system. Astrobiology 12, 258-270.

Feijoo, S. C., Cotton, L. N., Watson, C. E., and Martin, J. H. (1997). Effect of storage temperatures and ingredients on growth of Bacillus cereus in coffee creamers. J. Dairy Sci. 80, 1546-1553. doi: 10.3168/jds.S0022-0302(97)76084-3

Freese, E., Sass, H., Rütters, H., Schledjewski, R., and Rullkötter, J. (2008). Variable temperature-related changes in fatty acid composition of bacterial isolates from German Wadden sea sediments representing different bacterial phyla. Org. Geochem. 39, 1427-1438. doi: 10.1016/j.orggeochem.2008.06.005
Freiberg, C., Brunner, N. A., Schiffer, G., Lampe, T., Pohlmann, J., Brands, M., et al. (2004). Identification and characterization of the first class of potent bacterial acetyl-CoA carboxylase inhibitors with antibacterial activity. J. Biol. Chem. 279, 26066-26073. doi: 10.1074/jbc.M402989200

Fritze, D. (2004). Taxonomy of the genus Bacillus and related genera: the aerobic endospore-forming bacteria. Phytopathology 94, 1245-1248. doi: 10.1094/PHYTO.2004.94.11.1245

Fujihashi, M., Nakatani, T., Hirooka, K., Matsuoka, H., Fujita, Y., and Miki, K. (2014). Structural characterization of a ligand-bound form of Bacillus subtilis FadR involved in the regulation of fatty acid degradation. Proteins Struct. Funct. Bioinform. 82, 1301-1310. doi: 10.1002/prot.24496

Fujita, Y., Matsuoka, H., and Hirooka, K. (2007). Regulation of fatty acid metabolism in bacteria. Mol. Microbiol. 66, 829-839. doi: 10.1111/j.13652958.2007.05947.x

Fulco, A. J. (1967). The effect of temperature on the formation of delta 5unsaturated fatty acids by Bacilli. Biochim. Biophys. Acta 144, 701-703. doi: 10.1016/0005-2760(67)90065-3

Fulco, A. J. (1969). The biosynthesis of unsaturated fatty acids by Bacilli: I. Temperature induction of the desaturation reaction. J. Biol. Chem. 244, 889-895.

Fulco, A. J. (1972). The biosynthesis of unsaturated fatty acids by Bacilli: III. Uptake and utilization of exogenous palmitate. J. Biol. Chem. 247, 3503-3510.

Gonzalez-Pastor, J. E., Hobbs, E. C., and Losick, R. (2003). Cannibalism by sporulating bacteria. Science 301, 510-513. doi: 10.1126/science. 1086462

Grau, R., and De Mendoza, D. (1993). Regulation of the synthesis of unsaturated fatty acids by growth temperature in Bacillus subtilis. Mol. Microbiol. 8, 535542. doi: 10.1111/j.1365-2958.1993.tb01598.x

Guinebretiere, M., Auger, S., Galleron, N., Contzen, M., De Sarrau, B., De Buyser, M., et al. (2013). Bacillus cytotoxicus sp. nov. is a new thermotolerant species of the Bacillus cereus group occasionally associated with food poisoning. Int. J. Syst. Evol. Microbiol. 63, 31-40. doi: 10.1099/ijs.0. 030627-0

Guinebretiere, M. H., Berge, O., Normand, P., Morris, C., Carlin, F., and NguyenThe, C. (2001). Identification of bacteria in pasteurized zucchini purées stored at different temperatures and comparison with those found in other pasteurized vegetable purées. Appl. Environ. Microbiol. 67, 4520-4530. doi: 10.1128/AEM.67.10.4520-4530.2001

Guinebretiere, M. H., Thompson, F. L., Sorokin, A., Normand, P., Dawyndt, P., Ehling-Schulz, M., et al. (2008). Ecological diversification in the Bacillus cereus Group. Environ. Microbiol. 10, 851-865. doi: 10.1111/j.1462-2920.2007. 01495.x

Haque, M. A., and Russell, N. J. (2004). Strains of Bacillus cereus vary in the phenotypic adaptation of their membrane lipid composition in response to low water activity, reduced temperature and growth in rice starch. Microbiology 150, 1397-1404. doi: 10.1099/mic.0.26767-0

Harris, L. (1996). "Gram-positive organisms," in Automated Microbial Identification and Quantitation: Technologies for the 2000s, ed. W. P. Olson (Boca Raton, FL: CRC Press).

He, X., and Reynolds, K. A. (2002). Purification, characterization, and identification of novel inhibitors of the beta-ketoacyl-acyl carrier protein synthase III (FabH) from Staphylococcus aureus. Antimicrob. Agents Chemother. 46, 1310-1318. doi: 10.1128/AAC.46.5.1310-1318.2002

Heath, R. J., and Rock, C. O. (1996). Regulation of fatty acid elongation and initiation by acyl-acyl carrier protein in Escherichia coli. J. Biol. Chem. 271, 1833-1836. doi: 10.1074/jbc.271.44.27795

Heyndrickx, M., Vandemeulebroecke, K., Scheldeman, P., Hoste, B., Kersters, K., De Vos, P., et al. (1995). Paenibacillus (formerly Bacillus) gordonae (Pichinoty et al. 1986) Ash et al. 1994 is a later subjective synonym of Paenibacillus (formerly Bacillus) validus (Nakamura 1984) Ash et al. 1994: emended description of P. validus. Int. J. Syst. Bacteriol. 45, 661-669. doi: 10.1099/00207713-45-4-661

Hofemeister, J., Conrad, B., Adler, B., Hofemeister, B., Feesche, J., Kucheryava, N., et al. (2004). Genetic analysis of the biosynthesis of non-ribosomal peptideand polyketide-like antibiotics, iron uptake and biofilm formation by Bacillus subtilis A1/3. Mol. Genet. Genomics 272, 363-378. doi: 10.1007/s00438-0041056-y

Hou, C. T. (2008). New bioactive fatty acids. Asia Pac. J. Clin. Nutr. 1, 192-195. 
Hou, C. T. (2009). Biotechnology for fats and oils: new oxygenated fatty acids. N. Biotechnol. 26, 2-10. doi: 10.1016/j.nbt.2009.05.001

Hsueh, Y. H., Somers, E. B., and Wong, A. C. (2008). Characterization of the codY gene and its influence on biofilm formation in Bacillus cereus. Arch. Microbiol. 189, 557-568. doi: 10.1007/s00203-008-0348-8

Inda, M. E., Vandenbranden, M., Fernández, A., De Mendoza, D., Ruysschaert, J.-M., and Cybulski, L. E. (2014). A lipid-mediated conformational switch modulates the thermosensing activity of DesK. Proc. Natl. Acad. Sci. U.S.A. 111, 3579-3584. doi: 10.1073/pnas.1317147111

Ivy, R. A., Ranieri, M. L., Martin, N. H., Den Bakker, H. C., Xavier, B. M., Wiedmann, M., et al. (2012). Identification and characterization of psychrotolerant sporeformers associated with fluid milk production and processing. Appl. Environ. Microbiol. 78, 1853-1864. doi: 10.1128/AEM. 06536-11

Jiang, Z., Zhang, D. F., Khieu, T. N., Son, C. K., Zhang, X. M., Cheng, J., et al. (2014). Bacillus tianshenii sp. nov., isolated from a marine sediment sample. Int. J. Syst. Evol. Microbiol. 64, 1998-2002. doi: 10.1099/ijs.0.062224-0

Kämpfer, P. (1994). Limits and possibilities of total fatty acid analysis for classification and identification of Bacillus species. Syst. Appl. Microbiol. 17, 86-98. doi: 10.1016/S0723-2020(11)80035-4

Kaneda, T. (1969). Fatty acids in Bacillus larvae, Bacillus lentimorbus, and Bacillus popilliae. J. Bacteriol. 98, 143-146.

Kaneda, T. (1972). Positional preference of fatty acids in phospholipids of Bacillus cereus and its relation to growth temperature. Biochim. Biophys. Acta 280, 297-305. doi: 10.1016/0005-2760(72)90097-5

Kaneda, T. (1977). Fatty acids of the genus Bacillus: an example of branched-chain preference. Bacteriol. Rev. 41, 391-418.

Kaneda, T. (1991). Iso- and anteiso-fatty acids in bacteria: biosynthesis, function, and taxonomic significance. Microbiol. Rev. 55, 288-302.

Kaneda, T., Smith, E. J., and Naik, D. N. (1983). Fatty acid composition and primer specificity of de novo fatty acid synthetase in Bacillus globispores, Bacillus insolitus, and Bacillus psychrophilus. Can. J. Microbiol. 29, 1634-1641. doi: $10.1139 / \mathrm{m} 83-250$

Kang, H., Weerawongwiwat, V., Kim, J. H., Sukhoom, A., and Kim, W. (2013). Bacillus songklensis sp. nov., isolated from soil. Int. J. Syst. Evol. Microbiol. 63, 4189-4195. doi: 10.1099/ijs.0.050682-0

Kingston, A. W., Subramanian, C., Rock, C. O., and Helmann, J. D. (2011). A sigmaW-dependent stress response in Bacillus subtilis that reduces membrane fluidity. Mol. Microbiol. 81, 69-79. doi: 10.1111/j.1365-2958.2011.07679.x

Kito, M., and Pizer, L. I. (1969). Purification and regulatory properties of the biosynthetic L-glycerol 3-phosphate dehydrogenase from Escherichia coli. J. Biol. Chem. 244, 3316-3323.

Klangpetch, W., Nakai, T., Noma, S., Igura, N., and Shimoda, M. (2013). Combined effects of carbonation with heating and fatty acid esters on inactivation and growth inhibition of various Bacillus spores. J. Food Prot. 76, 1568-1574. doi: 10.4315/0362-028X.JFP-13-015

Kosowski, K., Schmidt, M., Pukall, R., Hause, G., Kampfer, P., and Lechner, U. (2014). Bacillus pervagus sp. nov. and Bacillus andreesenii sp. nov., isolated from a composting reactor. Int. J. Syst. Evol. Microbiol. 64, 88-94. doi: $10.1099 / \mathrm{ijs} .0 .054833-0$

Krishnamurthi, S., Ruckmani, A., Pukall, R., and Chakrabarti, T. (2010). Psychrobacillus gen. nov. and proposal for reclassification of Bacillus insolitus Larkin \& Stokes, 1967, B. psychrotolerans Abd-El Rahman et al., 2002 and B. psychrodurans Abd-El Rahman et al., 2002 as Psychrobacillus insolitus comb. nov., Psychrobacillus psychrotolerans comb. nov. and Psychrobacillus psychrodurans comb. nov. Syst. Appl. Microbiol. 33, 367-373. doi: $10.1016 /$ j.syapm.2010.06.003

Krulwich, T. A., Clejan, S., Falk, L. H., and Guffanti, A. A. (1987). Incorporation of specific exogenous fatty acids into membrane lipids modulates protonophore resistance in Bacillus subtilis. J. Bacteriol. 169, 4479-4485.

Lamanna, C., and Jones, L. (1963). Lethality for mice of vegetative and spore forms of Bacillus Cereus and Bacillus Cereus-like insect pathogens injected intraperitoneally and subcutaneously. J. Bacteriol. 85, 532-535.

Lang, D. R., and Lundgren, D. G. (1970). Lipid composition of Bacillus cereus during growth and sporulation. J. Bacteriol. 101, 483-489.

Lee, J. Y., Kim, Y. S., and Shin, D. H. (2002). Antimicrobial synergistic effect of linolenic acid and monoglyceride against Bacillus cereus and Staphylococcus aureus. J. Agric. Food Chem. 50, 2193-2199. doi: 10.1021/jf011175a
Lekogo, B. M., Coroller, L., Mathot, A. G., Mafart, P., and Leguerinel, I. (2010). Modelling the influence of palmitic, palmitoleic, stearic and oleic acids on apparent heat resistance of spores of Bacillus cereus NTCC 11145 and Clostridium sporogenes Pasteur 79.3. Int. J. Food Microbiol. 141, 242-247. doi: 10.1016/j.ijfoodmicro.2010.05.023

Li, B., Li, Q., Xu, Z., Zhang, N., Shen, Q., and Zhang, R. (2014). Responses of beneficial Bacillus amyloliquefaciens SQR9 to different soilborne fungal pathogens through the alteration of antifungal compounds production. Front. Microbiol. 5:636. doi: 10.3389/fmicb.2014.00636

Liu, Y., Lin, S., Zhang, X., Liu, X., Wang, J., and Lu, F. (2014). A novel approach for improving the yield of Bacillus subtilis transglutaminase in heterologous strains. J. Ind. Microbiol. Biotechnol. 20, 20. doi: 10.1007/s10295014-1468-6

Logan, N. A., Berge, O., Bishop, A. H., Busse, H.-J., De Vos, P., Fritze, D., et al. (2009). Proposed minimal standards for describing new taxa of aerobic, endospore-forming bacteria. Int. J. Syst. Evol. Microbiol. 59, 2114-2121. doi: 10.1099/ijs.0.013649-0

Lombardi, F. J., and Fulco, A. J. (1980). Temperature-mediated hyperinduction of fatty acid desaturation in pre-existing and newly formed fatty acids synthesized endogenously in Bacillus megaterium. Biochim. Biophys. Acta 618, 359-363. doi: 10.1016/0005-2760(80)90042-9

Lu, Y. J., Zhang, F., Grimes, K. D., Lee, R. E., and Rock, C. O. (2007). Topology and active site of PlsY: the bacterial acylphosphate:glycerol-3-phosphate acyltransferase. J. Biol. Chem. 282, 11339-11346. doi: 10.1074/jbc.M700374200

Lu, Y. J., Zhang, Y. M., and Rock, C. O. (2004). Product diversity and regulation of type II fatty acid synthases. Biochem. Cell Biol. 82, 145-155. doi: 10.1139/o03076

Mansilla, M., Aguilar, P. S., Albanesi, D., Cybulski, L. E., Altabe, S., and De Mendoza, D. (2003). Regulation of fatty acid desaturation in Bacillus subtilis. Prostaglandins Leukot Essent Fatty Acids 68, 187-190. doi: 10.1016/S09523278(02)00269-7

Marrakchi, H., Zhang, Y. M., and Rock, C. O. (2002). Mechanistic diversity and regulation of Type II fatty acid synthesis. Biochem. Soc. Trans. 30, 1050-1055. doi: 10.1042/BST0301050

Matsuoka, H., Hirooka, K., and Fujita, Y. (2007). Organization and function of the YsiA regulon of Bacillus subtilis involved in fatty acid degradation. J. Biol. Chem. 282, 5180-5194. doi: 10.1074/jbc.M606831200

Mondol, M. A., Shahidullah Tareq, F., Kim, J. H., Lee, M. A., Lee, H. S., Lee, J. S., et al. (2013). New antimicrobial compounds from a marine-derived Bacillus sp. J. Antibiot. 66, 89-95. doi: 10.1038/ja.2012.102

Morbidoni, H. R., De Mendoza, D., and Cronan, J. E. Jr. (1995). Synthesis of snglycerol 3-phosphate, a key precursor of membrane lipids, in Bacillus subtilis. J. Bacteriol. 177, 5899-5905.

Moss, C. W., and Lewis, V. J. (1967). Characterization of Clostridia by gas chromatography. I. Differentiation of species by cellular fatty acids. Appl. Microbiol. 15, 390-397.

Murínová, S., Dercová, K., Čertík, M., and Lászlová, K. (2014). The adaptation responses of bacterial cytoplasmic membrane fluidity in the presence of environmental stress factors - polychlorinated biphenyls and 3-chlorobenzoic acid. Biologia 69, 428-434.

Nazina, T. N., Tourova, T. P., Poltaraus, A. B., Novikova, E. V., Grigoryan, A. A., Ivanova, A. E., et al. (2001). Taxonomic study of aerobic thermophilic Bacilli: descriptions of Geobacillus subterraneus gen. nov., sp. nov. and Geobacillus uzenensis sp. nov. from petroleum reservoirs and transfer of Bacillus stearothermophilus, Bacillus thermocatenulatus, Bacillus thermoleovorans, Bacillus kaustophilus, Bacillus thermodenitrificans to Geobacillus as the new combinations G. stearothermophilus, G. th. Int. J. Syst. Evol. Microbiol. 51, 433-446.

Neidhardt, F. C. (1996). Escherichia coli and Salmonella: Cellular and Molecular Biology. Washington, DC: ASM Press.

Nickel, M., Homuth, G., Bohnisch, C., Mader, U., and Schweder, T. (2004). Cold induction of the Bacillus subtilis bkd operon is mediated by increased mRNA stability. Mol. Genet. Genomics 272, 98-107. doi: 10.1007/s00438-004-1038-0

Nickerson, K. W., and Bulla, L. A. (1980). Incorporation of Specific Fatty Acid Precursors During Spore Germination and Outgrowth in Bacillus thuringiensis. Appl. Environ. Microbiol. 40, 166-168.

Nihorimbere, V., Fickers, P., Thonart, P., and Ongena, M. (2009). Ecological fitness of Bacillus subtilis BGS3 regarding production of the surfactin lipopeptide 
in the rhizosphere. Environ. Microbiol. Rep. 1, 124-130. doi: 10.1111/j.17582229.2009.00017.x

Ongena, M., and Jacques, P. (2008). Bacillus lipopeptides: versatile weapons for plant disease biocontrol. Trends Microbiol. 16, 115-125. doi: 10.1016/j.tim.2007.12.009

Parsons, J. B., and Rock, C. O. (2013). Bacterial lipids: metabolism and membrane homeostasis. Prog. Lipid Res. 52, 249-276. doi: 10.1016/j.plipres.2013.02.002

Pasvolsky, R., Zakin, V., Ostrova, I., and Shemesh, M. (2014). Butyric acid released during milk lipolysis triggers biofilm formation of Bacillus species. Int. J. Food Microbiol. 181, 19-27. doi: 10.1016/j.ijfoodmicro.2014.04.013

Pathak, K. V., Bose, A., and Keharia, H. (2014). Identification and characterization of novel surfactins produced by fungal antagonist Bacillus amyloliquefaciens $6 \mathrm{~B}$. Biotechnol. Appl. Biochem. 61, 349-356. doi: 10.1002/bab.1174

Pech-Canul, Á., Nogales, J., Miranda-Molina, A., Álvarez, L., Geiger, O., Soto, M. J., et al. (2011). FadD is required for utilization of endogenous fatty acids released from membrane lipids. J. Bacteriol. 193, 6295-6304. doi: 10.1128/JB.05450-11

Pedrido, M. E., De Ona, P., Ramirez, W., Lenini, C., Goni, A., and Grau, R. (2013). Spo0A links de novo fatty acid synthesis to sporulation and biofilm development in Bacillus subtilis. Mol Microbiol 87, 348-367. doi: $10.1111 / \mathrm{mmi} .12102$

Peng, Q., Wang, G., Liu, G., Zhang, J., and Song, F. (2015). Identification of metabolism pathways directly regulated by sigma(54) factor in Bacillus thuringiensis. Front. Microbiol. 6:407. doi: 10.3389/fmicb.2015.00407

Petrackova, D., Vecer, J., Svobodova, J., and Herman, P. (2010). Long-term adaptation of Bacillus subtilis 168 to extreme $\mathrm{pH}$ affects chemical and physical properties of the cellular membrane. J. Membr. Biol. 233, 73-83. doi: 10.1007/s00232-010-9226-9

Pettersson, B., Rippere, K. E., Yousten, A. A., and Priest, F. G. (1999). Transfer of Bacillus lentimorbus and Bacillus popilliae to the genus Paenibacillus with emended descriptions of Paenibacillus lentimorbus comb. nov. and Paenibacillus popilliae comb. nov. Int. J. Syst. Bacteriol. 49, 531-540. doi: 10.1099/00207713-49-2-531

Piggot, P. J., and Hilbert, D. W. (2004). Sporulation of Bacillus subtilis. Curr. Opin Microbiol. 7, 579-586. doi: 10.1016/j.mib.2004.10.001

Pirttijärvi, T. S., Andersson, M. A., and Salkinoja-Salonen, M. S. (2000). Properties of Bacillus cereus and other Bacilli contaminating biomaterial-based industrial processes. Int. J. Food Microbiol. 60, 231-239. doi: 10.1016/S01681605(00)00313-5

Pirttijärvi, T. S. M., Ahonen, L. M., Maunuksela, L. M., and Salkinoja-Salonen, M. S. (1998). Bacillus cereus in a whey process. Int. J. Food Microbiol. 44, 31-41. doi: 10.1016/S0168-1605(98)00117-2

Planchon, S., Dargaignaratz, C., Levy, C., Ginies, C., Broussolle, V., and Carlin, F. (2011). Spores of Bacillus cereus strain $\mathrm{KBAB} 4$ produced at $10^{\circ} \mathrm{C}$ and $30^{\circ} \mathrm{C}$ display variations in their properties. Food Microbiol. 28, 291-297. doi: 10.1016/j.fm.2010.07.015

Qiu, F., Zhang, X., Liu, L., Sun, L., Schumann, P., and Song, W. (2009). Bacillus beijingensis sp. nov. and Bacillus ginsengi sp. nov., isolated from ginseng root. Int. J. Syst. Evol. Microbiol. 59, 729-734. doi: 10.1099/ijs.0. 65861-0

Ramos, J. L., Gallegos, M. T., Marques, S., Ramos-Gonzalez, M. I., EspinosaUrgel, M., and Segura, A. (2001). Responses of Gram-negative bacteria to certain environmental stressors. Curr. Opin. Microbiol. 4, 166-171. doi: 10.1016/S1369-5274(00)00183-1

Ray, T. K., and Cronan, J. E. Jr. (1987). Acylation of glycerol 3-phosphate is the sole pathway of de novo phospholipid synthesis in Escherichia coli. J. Bacteriol. 169, 2896-2898.

Reddy, G. S., Uttam, A., and Shivaji, S. (2008). Bacillus cecembensis sp. nov., isolated from the Pindari glacier of the Indian Himalayas. Int. J. Syst. Evol. Microbiol. 58, 2330-2335. doi: 10.1099/ijs.0.65515-0

Rock, C. O., and Cronan, J. E. (1996). Escherichia coli as a model for the regulation of dissociable (type II) fatty acid biosynthesis. Biochim. Biophys. Acta 12, 1-16. doi: 10.1016/0005-2760(96)00056-2

Rock, C. O., and Jackowski, S. (1982). Regulation of phospholipid synthesis in Escherichia coli. Composition of the acyl-acyl carrier protein pool in vivo. J. Biol. Chem. 257, 10759-10765.

Romano, A., Vitullo, D., Senatore, M., Lima, G., and Lanzotti, V. (2013). Antifungal cyclic lipopeptides from Bacillus amyloliquefaciens strain BO5A. J. Nat. Prod. 76, 2019-2025. doi: 10.1021/np400119n
Rosenfeld, E., Duport, C., Zigha, A., and Schmitt, P. (2005). Characterization of aerobic and anaerobic vegetative growth of the food-borne pathogen Bacillus cereus F4430/73 strain. Can. J. Microbiol. 51, 149-158. doi: 10.1139/ w04-132

Sasser, M. (1990). Bacterial Identification by Gas Chromatographic Analysis of Fatty Acids Methyl Esters (GC-FAME). Newark, DE: MIDI Labs, Inc.

Scandella, C. J., and Kornberg, A. (1969). Biochemical studies of bacterial sporulation and germination. XV. Fatty acids in growth, sporulation, and germination of Bacillus megaterium. J. Bacteriol. 98, 82-86.

Scheuerbrandt, G., and Bloch, K. (1962). Unsaturated fatty acids in microorganisms. J. Biol. Chem. 237, 2064-2068.

Schujman, G. E., Choi, K. H., Altabe, S., Rock, C. O., and De Mendoza, D. (2001). Response of Bacillus subtilis to cerulenin and acquisition of resistance. J. Bacteriol. 183, 3032-3040. doi: 10.1128/JB.183.10.3032-3040.2001

Schujman, G. E., Grau, R., Gramajo, H. C., Ornella, L., and De Mendoza, D. (1998). De novo fatty acid synthesis is required for establishment of cell type-specific gene transcription during sporulation in Bacillus subtilis. Mol. Microbiol. 29, 1215-1224. doi: 10.1046/j.1365-2958.1998.01004.x

Schujman, G. E., Paoletti, L., Grossman, A. D., and De Mendoza, D. (2003). FapR, a bacterial transcription factor involved in global regulation of membrane lipid biosynthesis. Dev. Cell 4, 663-672. doi: 10.1016/S1534-5807(03)00123-0

Seiler, H., Wenning, M., Schmidt, V., and Scherer, S. (2013). Bacillus gottheilii sp. nov., isolated from a pharmaceutical manufacturing site. Int. J. Syst. Evol. Microbiol. 63, 867-872. doi: 10.1099/ijs.0.036277-0

Shearer, A. E., Dunne, C. P., Sikes, A., and Hoover, D. G. (2000). Bacterial spore inhibition and inactivation in foods by pressure, chemical preservatives, and mild heat. J. Food Prot. 63, 1503-1510.

Shida, O., Takagi, H., Kadowaki, K., Nakamura, L. K., and Komagata, K. (1997). Transfer of Bacillus alginolyticus, Bacillus chondroitinus, Bacillus curdlanolyticus, Bacillus glucanolyticus, Bacillus kobensis, and Bacillus thiaminolyticus to the genus Paenibacillus and emended description of the genus Paenibacillus. Int. J. Syst. Bacteriol. 47, 289-298. doi: 10.1099/00207713-47-2-289

Shobharani, P., and Halami, P. M. (2014). Cellular fatty acid profile and $\mathrm{H}(+)$-ATPase activity to assess acid tolerance of Bacillus sp. for potential probiotic functional attributes. Appl. Microbiol. Biotechnol. 98, 9045-9058. doi: 10.1007/s00253-014-5981-3

Sikorski, J., Brambilla, E., Kroppenstedt, R. M., and Tindall, B. J. (2008). The temperature-adaptive fatty acid content in Bacillus simplex strains from 'Evolution Canyon', Israel. Microbiology 154, 2416-2426. doi: 10.1099/mic.0.2007/016105-0

Sinensky, M. (1971). Temperature control of phospholipid biosynthesis in Escherichia coli. J. Bacteriol. 106, 449-455.

Slack, F. J., Serror, P., Joyce, E., and Sonenshein, A. L. (1995). A gene required for nutritional repression of the Bacillus subtilis dipeptide permease operon. Mol. Microbiol. 15, 689-702. doi: 10.1111/j.1365-2958.1995.tb02378.x

Smoot, L. A., and Pierson, M. D. (1981). Mechanisms of sorbate inhibition of Bacillus cereus $T$ and Clostridium botulinum $62 \mathrm{~A}$ spore germination. Appl. Environ. Microbiol. 42, 477-483.

Song, Y., Yang, R., Guo, Z., Zhang, M., Wang, X., and Zhou, F. (2000). Distinctness of spore and vegetative cellular fatty acid profiles of some aerobic endospore-forming Bacilli. J. Microbiol. Methods 39, 225-241. doi: 10.1016/S0167-7012(99)00123-2

Subhash, Y., Sasikala, C., and Ramana, ChV. (2014). Bacillus luteus sp. nov., isolated from soil. Int. J. Syst. Evol. Microbiol. 64, 1580-1586. doi: 10.1099/ijs.0.066225-0

Tang, J., Yang, G., Wen, J., Yu, Z., Zhou, S., and Liu, Z. (2014). Bacillus thermophilum sp. nov., isolated from a microbial fuel cell. Arch. Microbiol. 196, 629-634. doi: 10.1007/s00203-014-1001-3

Ter Beek, A., Keijser, B. J., Boorsma, A., Zakrzewska, A., Orij, R., Smits, G. J., et al. (2008). Transcriptome analysis of sorbic acid-stressed Bacillus subtilis reveals a nutrient limitation response and indicates plasma membrane remodeling. J. Bacteriol. 190, 1751-1761. doi: 10.1128/JB.01516-07

Tojo, S., Satomura, T., Matsuoka, H., Hirooka, K., and Fujita, Y. (2011). Catabolite repression of the Bacillus subtilis FadR regulon, which is involved in fatty acid catabolism. J. Bacteriol. 193, 2388-2395. doi: 10.1128/JB.00016-11

Uetanabaro, A. P., Wahrenburg, C., Hunger, W., Pukall, R., Spröer, C., Stackebrandt, E., et al. (2003). Paenibacillus agarexedens sp. nov., nom. rev., and 
Paenibacillus agaridevorans sp. nov. Int. J. Syst. Evol. Microbiol. 53, 1051-1057. doi: 10.1099/ijs.0.02420-0

Van Melis, C. C. J., Nierop Groot, M. N., Tempelaars, M. H., Moezelaar, R., and Abee, T. (2011). Characterization of germination and outgrowth of sorbic acid-stressed Bacillus cereus ATCC 14579 spores: Phenotype and transcriptome analysis. Food Microbiol. 28, 275-283. doi: 10.1016/j.fm.2010.04.005

Van Pham, H. T., and Kim, J. (2014). Bacillus thaonhiensis sp. nov., a new species, was isolated from the forest soil of Kyonggi University by using a modified culture method. Curr. Microbiol. 68, 88-95. doi: 10.1007/s00284-0130443-1

Van Schaijk, B. C., Kumar, T. R., Vos, M. W., Richman, A., Van Gemert, G. J., Li, T., et al. (2014). Type II fatty acid biosynthesis is essential for Plasmodium falciparum sporozoite development in the midgut of Anopheles mosquitoes. Eukaryot. Cell 13, 550-559. doi: 10.1128/EC.00264-13

Van Schaik, W., Chateau, A., Dillies, M. A., Coppee, J. Y., Sonenshein, A. L., and Fouet, A. (2009). The global regulator CodY regulates toxin gene expression in Bacillus anthracis and is required for full virulence. Infect. Immun. 77, 4437-4445. doi: 10.1128/IAI.00716-09

Vasiurenko, Z. P., Kolisnichenko, N. I., and Khramova, N. I. (1984). [Taxonomic significance of the fatty acid composition of bacteria of the genera Bordetella and Haemophilus]. Zh. Mikrobiol. Epidemiol. Immunobiol. 1, 26-31.

Vos, P., Garrity, G., Jones, D., Krieg, N. R., Ludwig, W., Rainey, F. A., et al. (2011). Bergey's Manual of Systematic Bacteriology: Volume 3: The Firmicutes. Berlin: Springer Science \& Business Media.

Wang, Y. Q., Yuan, Y., Yu, Z., Yang, G. Q., and Zhou, S. G. (2013). Bacillus borbori sp. Nov., isolated from an electrochemically active biofilm. Curr. Microbiol. 67, 718-724. doi: 10.1007/s00284-013-0426-2

Weber, F. J., and De Bont, J. A. (1996). Adaptation mechanisms of microorganisms to the toxic effects of organic solvents on membranes. Biochim. Biophys. Acta 29, 225-245. doi: 10.1016/S0304-4157(96)00010-X

Weerkamp, A., and Heinen, W. (1972). Effect of temperature on the fatty acid composition of the extreme thermophiles, Bacillus caldolyticus and Bacillus caldotenax. J. Bacteriol. 109, 443-446.

White, S. W., Zheng, J., Zhang, Y.-M., and Rock, C. O. (2005). The structural biology of type II fatty acid biosynthesis. Annu. Rev. Biochem. 74, 791-831. doi: 10.1146/annurev.biochem.74.082803.133524

Wiegeshoff, F., Beckering, C. L., Debarbouille, M., and Marahiel, M. A. (2006). Sigma L is important for cold shock adaptation of Bacillus subtilis. J. Bacteriol. 188, 3130-3133. doi: 10.1128/JB.188.8.3130-3133.2006

Willecke, K., and Pardee, A. B. (1971). Fatty acid-requiring mutant of Bacillus subtilis defective in branched chain $\alpha$-keto acid dehydrogenase. J. Biol. Chem. 246, 5264-5272.

Yano, Y., Nakayama, A., Ishihara, K., and Saito, H. (1998). Adaptive changes in membrane lipids of barophilic bacteria in response to changes in growth pressure. Appl. Environ. Microbiol. 64, 479-485.

Yao, M., Walker, H. W., and Lillard, D. A. (1970). Fatty acids from vegetative cells and spores of Bacillus stearothermophilus. J. Bacteriol. 102, 877-878.
Yoon, J. H., Lee, K. C., Weiss, N., Kho, Y. H., Kang, K. H., and Park, Y. H. (2001). Sporosarcina aquimarina sp. nov., a bacterium isolated from seawater in Korea, and transfer of Bacillus globisporus (Larkin and Stokes 1967), Bacillus psychrophilus (Nakamura 1984) and Bacillus pasteurii (Chester 1898) to the genus Sporosarcina as Sporosarcina globispora comb. nov., Sporosarcina psychrophila comb. nov. and Sporosarcina pasteurii comb. nov., and emended description of th. Int. J. Syst. Evol. Microbiol. 51, 1079-1086. doi: 10.1099/00207713-51-3-1079

Yoshimura, M., Oshima, T., and Ogasawara, N. (2007). Involvement of the YneS/YgiH and PlsX proteins in phospholipid biosynthesis in both Bacillus subtilis and Escherichia coli. BMC Microbiol. 7:69. doi: 10.1186/14712180-7-69

Yu, Y., Li, H. R., Zeng, Y. X., and Chen, B. (2011). Bacillus beringensis sp. nov., a psychrotolerant bacterium isolated from the Bering Sea. Antonie Van Leeuwenhoek 99, 551-557. doi: 10.1007/s10482-010-9523-4

Yu, Z., Wang, Y., Qin, D., Yang, G., and Zhou, S. (2013). Bacillus sediminis sp. nov., isolated from an electroactive biofilm. Antonie Van Leeuwenhoek 104, 1109-1116. doi: 10.1007/s10482-013-0032-0

Yumoto, I., Yamazaki, K., Hishinuma, M., Nodasaka, Y., Inoue, N., and Kawasaki, K. (2000). Identification of facultatively alkaliphilic Bacillus sp. strain YN-2000 and its fatty acid composition and cell-surface aspects depending on culture pH. Extremophiles 4, 285-290. doi: 10.1007/s007920070015

Zhai, L., Liao, T., Xue, Y., and Ma, Y. (2012). Bacillus daliensis sp. nov., an alkaliphilic, Gram-positive bacterium isolated from a soda lake. Int. J. Syst. Evol. Microbiol. 62, 949-953. doi: 10.1099/ijs.0.031575-0

Zhang, Y. M., and Rock, C. O. (2008). Membrane lipid homeostasis in bacteria. Nat. Rev. Microbiol. 6, 222-233. doi: 10.1038/nrmicro1839

Zhao, F., Feng, Y. Z., Chen, R. R., Zhang, H. Y., Wang, J. H., and Lin, X. G. (2014). Bacillus fengqiuensis sp. nov., isolated from a typical sandy loam soil under long-term NPK fertilization in the North China. Int. J. Syst. Evol. Microbiol. 64, 2849-2856. doi: 10.1099/ijs.0.063081-0

Zhu, B., Xia, X., Xia, N., Zhang, S., and Guo, X. (2014). Modification of Fatty acids in membranes of bacteria: implication for an adaptive mechanism to the toxicity of carbon nanotubes. Environ. Sci. Technol. 48, 4086-4095. doi: $10.1021 /$ es404359v

Conflict of Interest Statement: The authors declare that the research was conducted in the absence of any commercial or financial relationships that could be construed as a potential conflict of interest.

Copyright (c) 2015 Diomandé, Nguyen-The, Guinebretière, Broussolle and Brillard. This is an open-access article distributed under the terms of the Creative Commons Attribution License (CC BY). The use, distribution or reproduction in other forums is permitted, provided the original author(s) or licensor are credited and that the original publication in this journal is cited, in accordance with accepted academic practice. No use, distribution or reproduction is permitted which does not comply with these terms. 